\title{
Capítulo 3 \\ La metáfora de la matriz: \\ la mujer muisca y su rol \\ en la "complementariedad" \\ y reivindicación del poder femenino
}

\section{En busca de la complementariedad perdida}

En el capítulo anterior hemos logrado identificar dos elementos importantes en nuestra argumentación. En primera medida, que se presenta una paradoja resultante del contraste entre la relevante figura de la mujer y de lo femenino en la cosmovisión muisca y las dificultades que las mismas han tenido para consolidar su liderazgo en los procesos políticos y espirituales que hacen parte de la indigenidad muisca contemporánea.

En segunda medida, que la indigenidad muisca ha sido un proceso de elaboración discursiva que se ha configurado recientemente en el marco del surgimiento de los cabildos muiscas en Bosa y Suba que a su vez se alimenta de la memoria de vivencias, costumbres, repertorios, imágenes, estilos de vida y cuerpos morales que las mujeres recuerdan como parte de una niñez y juventud campesina, que hoy día ha sido re-significada como fundamento de una memoria indígena que había permanecido mimetizada, resistente, en silencio, y presta a ser "despertada", interpretada, asumida e incorporada como base de su indigenidad. 
Consecuentemente, en la actualidad parte de las mujeres muiscas de hoy se identifican y reconocen como indígenas, como resultado de un proceso de conciencia, aprendizaje y organización comunitaria complejo, y desde esa misma conciencia están dispuestas a reflexionar activamente sobre la importancia de su rol y liderazgo, así como de los obstáculos que a veces impiden que tales se desarrollen potencialmente. En ese orden de ideas, se espera que emerjan debates en torno a las relaciones con los roles y figuras masculinas. El hombre, en esa medida, a veces cumple la posición dominante y obstaculizadora en el discurso, es una figura a la que la mujer debe confrontar y hasta oponerse.

Otras veces es integrada de manera conciliadora en la imagen típica de la complementariedad de los principios femenino-masculino. La complementariedad es el concepto dualista que significa que dos elementos no se oponen por sus diferencias hasta imponerse sobre el otro, sino que se completan mutuamente y que en dicha conjunción contribuyen a potencializar las capacidades de cada uno. Sin embargo, una tendencia en las reflexiones de las mujeres muiscas que conversaron con nosotros es afirmar que el machismo actual en los procesos organizativos indígenas indica una deuda moral de los hombres hacia las mujeres.

Yilena, mujer joven de la comunidad muisca de Suba, en una charla espontánea que surgió de este tema mientras alistábamos plantas que harían parte de la preparación de una medicina de tabaco en Nemocón, recordó que una vez hubo un círculo de palabra o reunión indígena al pie de la laguna ubicada en el campus de la Universidad Nacional de Colombia en Bogotá. La reunión era conducida por Sua Yé, hombre líder y fundador de la comunidad muisca de Ráquira. En medio del encuentro, una mujer insistía contundentemente en la importancia de recuperar la "palabra femenina" en el rescate cultural muisca. Como también es tendencia en las intervenciones femeninas en estos espacios, la mujer reclamaba de cierta manera que se aplicara la coherencia que contradiría la paradoja analizada inicialmente en este texto; en otras palabras, exigía que la mujer muisca de hoy tuviera la importancia que se fundamenta en las figuras femeninas primordiales del Pueblo Muisca. Yilena, como mujer, recuerda gratamente que el líder masculino manifestó la importancia de transformar las relaciones de género 
en las comunidades indígenas, e incluso le respondió a la interlocutora con unas palabras que conectaban creativamente la situación actual con estructuras históricas más complejas y de largo aliento:

\begin{abstract}
Hubo un momento en que Sua Yé la interrumpió y le dijo: 'mire, yo entiendo que ustedes como madres estén dolidas, fueron años y años de maltrato que están presentes en su memoria, pero nosotros como hombres también nos disculpamos por todo lo que hicimos, pero también les pedimos que tengan paciencia porque hasta ahora estamos dando los primeros pasos, ténganos paciencia, y de a poco ese lugar va a volver a recuperarse' (Yilena, comunicación personal, septiembre 5 de 2015).
\end{abstract}

La frase de Sua Yé marca un tropo que también es tendencia en las interpretaciones históricas que los muiscas elaboran sobre las afectaciones coloniales y sus procesos de resistencia y revitalización étnica: en el pasado bubo un orden y unos lugares que se perdieron y que hay que recuperar. La frase, como veremos más adelante, también parece esconder que la mujer sufrió el dolor y el maltrato por dos causantes: el patriarcado traído de afuera, de los conquistadores, y el "aparente" machismo que la colonización impregnó en la conciencia masculina indígena. El calificativo de "aparente" tiene sentido, pues invita a reflexionar sobre las posiciones que la academia ha desarrollado frente a la dualidad y a la complementariedad como características de las relaciones de poder y de género en las culturas indígenas.

Para Elena Rey (2009), la dualidad y la complementariedad son conceptos presentes en la mayoría de cosmovisiones indígenas. La dualidad se basa en todos los elementos del universo que se relacionan como dualidades (cielo-tierra, felicidad-tristeza, hombre-mujer, luz-oscuridad) y la complementariedad como una dualidad entre lo masculino y lo femenino en la que el hombre y la mujer son contrarios que se complementan armónicamente y, consecuentemente, mediante esto replican el equilibrio esperado entre los elementos de la naturaleza (p. 14). El tropo del lugar que se perdió y debe ser recuperado hace parte, de acuerdo con la lectura que hacemos de Rey (2009), de la visión más conservadora sobre 
la complementariedad, la cual la define como una característica innata de las sociedades indígenas y presupone una relación siempre armónica entre lo femenino y lo masculino.

Pero hay otra corriente crítica o revisionista que en principio propone que la complementariedad es algo que hay que "recuperar" y construir nuevamente. Más aún, existen argumentos teóricos que ponen en duda la existencia de tal armonización e igualdad de géneros en el pasado indígena y que, por tanto, proponen incluso que las tradiciones deben ser reinterpretadas para garantizar la equidad entre hombres y mujeres en las sociedades indígenas de hoy. Como ejemplo representativo, mujeres indígenas de comunidades antioqueñas (emberás y senúes) han llegado a revisar los mitos de origen que aparentemente legitimaban la violencia masculina hacia la mujer para proponer interpretaciones que llevan a rescatar la complementariedad, la equidad y un rol femenino para nada relacionado con la sumisión y la objetivación de la violencia de género (Caviedes, 2009).

En el marco de los procesos de memoria cultural llevados a cabo por las mujeres muiscas se ha visto la necesidad de revisar críticamente aquellos elementos que en la cosmovisión y en la historia antigua aportan y permiten la interpretación de la aparente complementariedad que se perdió entre mujeres y hombres por el proceso colonizador. No podemos afirmar desde este estudio si esta, la complementariedad, hizo parte o no de las sociedades muiscas de antaño de manera innata, pero sí que desde estas revisiones las comunidades muiscas de hoy configuran cuerpos de valores, mapas conceptuales y esquemas de relaciones de género que buscan otorgarle un rol relevante a la mujer. Para ello rescatan de la mitología, de la etnohistoria y hasta de nuevas interpretaciones históricas aquellas figuras, ideas y reflexiones que sustenten el empoderamiento femenino y la complementariedad equitativa con el poder masculino.

El presente capítulo propone elaborar una argumentación a partir de la gran narrativa propuesta por las mujeres muiscas: la historia de un poder femenino que, en complemento con lo masculino, alguna vez ocupó un lugar relevante en la cultura muisca; con la llegada de Occidente tal poder se perdió y el machismo invadió la conciencia del hombre muisca, lo que trajo muchos cambios en torno a la familia y 
la sociedad general; la necesidad actual es la de rescatar tal complementariedad para garantizar la salud comunitaria que represente procesos organizativos más eficientes y un pueblo muisca fortalecido en su identidad, memoria y moralidad.

Argumentaremos que, independientemente de verificar si es innata en la historia del pueblo muisca, la complementariedad es hoy un campo de relaciones de género que las mujeres buscan consolidar para garantizar un rol relevante y un equilibrio de poderes en los procesos tanto políticos como medicinales-espirituales. Para ello nos basaremos en el análisis de datos obtenidos mediante observación participante y entrevistas abiertas en el marco de reuniones comunitarias de la casa de medicina Zhue Gata, de ceremonias de pagamento en territorios de Bosa y de procesos de preparación de medicinas para la salud comunitaria. A medida que los relatos etnográficos se desarrollan, se irán integrando elementos de la mitología y de la historia que hacen parte de las interpretaciones desde las que las mujeres muiscas de hoy legitiman su poder y relevancia.

\section{Complementariedad y dualidad en la cosmovisión muisca}

Estudiar la mitología muisca y la manera como sus diferentes contenidos han sido privilegiados u omitidos de acuerdo a su incorporación en textos escritos desde la Conquista es un campo complejo que no es el eje del presente análisis. Sin embargo, debemos partir de la idea de que en la medida en que los mitos registrados desde el siglo XVI han hecho parte de producciones literarias y académicas que han forjado la imagen del pueblo muisca como unidad cultural, varios de los personajes, sucesos y acciones presentes en los relatos son en la actualidad insumos fundamentales para que las comunidades contemporáneas elaboren los cimientos morales desde los que basan las relaciones entre el pasado lejano y las acciones políticas y reivindicativas del presente.

Ya hemos afirmado repetitivamente que una rutina presente en casi todos los espacios de congregación de las comunidades muiscas de hoy es la de iniciar con un saludo verbal - a veces acompañado de 
rutinas corporales- a "Padre" y "Madre". De esta manera, el muisca contemporáneo reconoce la dualidad de las entidades creadoras y regidoras del universo. Podríamos afirmar que en cuanto al mito cosmogónico la complementariedad de lo femenino y lo masculino es indiscutible. Para Correa (2004) el origen del universo en la mitología muisca es fruto del matrimonio cósmico entre el poder masculino del sol y el femenino de la luna.

La unión entre estos dos astros marca una dualidad arquetípica que se va a replicar sistemáticamente en muchos "cuerpos" que hacen parte del universo cosmológico muisca. De esta manera, las tensiones calor-frío, luz-oscuridad, día-noche, positivo-negativo, entre otras, generan una codificación presente en el mito que explica "los movimientos de los flujos de energía en circulación” (Rozo, 1999, p. 40) presentes en los elementos del cosmos y la naturaleza. Por lo general, lo masculino estaba presente en la dimensión del "arriba", del sol, del pensamiento, de la fecundidad, mientras lo femenino en la del “abajo", de la tierra, del agua, de la matriz y de la fertilidad (Correa, 2004).

La dualidad, femenino-masculino, se refuerza mediante hallazgos arqueológicos e interpretaciones de los símbolos presentes en las figuras votivas muiscas, es decir, aquellos objetos usados en el mundo chamánico para establecer la comunicación con los dioses y augurar situaciones positivas esperadas por los mortales. Roberto Lleras Pérez (2005) afirma que el mundo muisca se definía por dualismos, por parejas, donde la más popular era la de femenino-masculino y que precisamente el chamanismo - que significaría el campo de autoridades y prácticas religiosas llevadas a cabo por especialistas masculinos- busca el equilibrio, el cual no es permanente, ya que hay situaciones que lo afectan periódicamente de forma parcial y transitoria (Lleras, 2005, p. 65).

De esta manera, lo femenino y lo masculino no solo hacen presencia como fuerzas que se complementan en los diferentes elementos cósmicos, sino que para ser principios reguladores deben entrar en cierta confrontación y por eso la sociedad muisca, tanto antigua como contemporánea, establece ideas, interpretaciones y rutinas de trabajo para manejar y controlar el equilibrio y los flujos de tal dualidad. Esta idea es muy relevante a la hora de argumentar en el presente el 
poder femenino que se reclama por parte de las mujeres y que ahondaremos más adelante.

Una de las primeras tensiones que se dan en la relación, masculino-femenino a partir del mito cosmogónico es la siguiente: a nivel general, Chiminigagua, luz del Sol, es la entidad caracterizada como masculina que da origen al universo. Sin embargo, en otras versiones del mito aparece la entidad femenina Bagué como la originaria y previa a Chiminigagua. Esto significaría que, al seguir esta última versión, el poder femenino ocuparía un lugar, por lo menos, inicial cronológicamente y anterior al masculino. Aun así, en las narraciones actuales de los muiscas tal tensión se soluciona por lo general con el saludo equitativo a "Padre" y "Madre" como ya lo afirmamos anteriormente. En otras ocasiones hemos registrado versiones mitológicas contemporáneas por parte de líderes de medicina en las que el origen del universo es fruto de la danza entre Padre y Madre, quienes al copular se unen formando una espiral mientras generan el sonido primordial de la serpiente: “zzzzz". Fruto de tal unión, emergió Chiminigagua. Sea cual sea la versión producida y transmitida en cada comunidad actual, la complementariedad es imperativa y nunca busca resaltar a un creador masculino único, en contravía con la tradición judeocristiana.

Al revisar juiciosamente la producción etnohistórica de los cronistas, Correa (2004) encuentra en los registros sobre la mitología que existen dos versiones encontradas sobre la antropogénesis muisca. Acá la revisaremos brevemente con el fin de comprender cómo afecta la relación entre lo masculino y lo femenino. Según Correa (2004), los cronistas Castellanos y Simón coinciden en otorgarle a Bachué, diosa primordial de lo muisca, el rol de creadora y primera ordenadora de la humanidad. Según el mito, Bachué emergió de la laguna de Iguaque, cerca de Villa de Leyva, con un niño en sus brazos llamado Fuchunsúa, quien no era su hijo, sino su compañero. Al crecer este, se reproducirían y gestarían a la humanidad. Bachué brinda las primeras enseñanzas a los hombres y retorna con su compañero a la laguna en forma de serpientes.

El mito aporta tres ideas en relación con el rol de lo femenino. En primer lugar, legitima la figura de la "matriz" como dadora de vida y como receptora de la muerte o finalización de ciclos vitales, es decir, 
quien marca las transiciones en la vida de las personas y de los elementos del cosmos; en segundo lugar, su rol como "ordenadora" y "educadora", como transmisora principal de la cultura; y en tercer lugar, como poder creador que debe ser renovado y actualizado en la ritualidad. Correa (2004) lo explica así:

[...] la transición pasa de la vida intrauterina del niño a su fecunda madurez, para retornar a ese más allá [...] el relato también explica la antropogénesis como transición de la indiferencia natural al orden social, de las nieblas al orden y la ceremonia [...] describe el poder procreador de la mujer, su gestación de la humanidad y la instauración del rito que se realizaba en las aguas para memoria de los hechos primordiales y reactualización de sus poderes procreativos (pp. 49-50).

La tensión se da cuando según Correa (2004), el mismo cronista Simón registra un mito diferente de creación de la humanidad muisca en los pueblos de lo que hoy es Boyacá. Iraca tenía a un sobrino de nombre Ramiriqui; ambos se convirtieron en los primeros caciques, es decir, en los representantes masculinos del poder político muisca. También crearon a los hombres de tierra amarilla y a las mujeres con unas yerbas altas de tronco hueco. Lo interesante viene después y tiene dos implicaciones. En primer lugar, Iraca, que es el mismo Sogamoso, se convierte en luna, es decir toma el poder otorgado a lo femenino. Es interesante, porque en la tradición de la ideología solar muisca, Sogamoso es la tierra del sol-masculino por antonomasia.

En segundo lugar, en esta trasposición el poder femenino es tomado por el cacique de mayor jerarquía, es decir que la luna terminó ordenando al sol, con lo cual este se reivindica como de mucha relevancia y para nada sumiso al masculino. Si a esta dualidad se le suma la presente en la versión de la entidad primordial Bagué, que anticipa a Chiminigagua, la fuerza femenina es indispensable y prioritaria. En ambos relatos se configura una relación en la que lo femenino guía a lo masculino, es mayor y más grande y de cierta manera lo anticipa y ordena. 
El punto anterior cobra mucha importancia en nuestro análisis, debido entre otras a las lecturas que las mujeres muiscas dan hoy día a estos contenidos de los mitos registrados. Nuevamente Yilena nos aporta una reflexión al respecto:

[...] cuando veníamos en el bus hablábamos de eso, Edwin decía que en las crónicas de los españoles, las crónicas de la Iglesia, no se nombra a ninguna cacica, a ninguna sacerdotisa, a ninguna, muy poco a la que nombren, pero casi siempre -Edwin interrumpe y dice que solo nombran a Soratama - nombran son Guatavita, Siecha, referenciando digamos lo femenino, Bachué, Bagué, Chía, Huitaca, pero de ahí no se pasa (Yilena, comunicación personal, septiembre 5 de 2015). ${ }^{1}$

Aunque es cierto que las figuras históricas más relevantes del pasado muisca son hombres, lo cual se repite sistemáticamente en la historia de las organizaciones indígenas contemporáneas —donde se privilegian nombres de "abuelos" y hombres fundadores de comunidades y procesos organizativos-, Yilena parece otorgarle poca relevancia a lo que nombra como "lo femenino". Sin embargo consideramos que la presencia de lo femenino como fuerza y principio creador-ordenador más que como personificación de autoridades históricas es un indicador noble de lo que puede legitimarse hoy como el rol de lo femenino en las comunidades muiscas.

Sin embargo, el estudio de Correa (2004) aporta otros elementos que alimentan la tensión entre el poder femenino y el masculino. La tesis principal del investigador es que el sistema de poder masculino, representado en el cacicazgo, fue fruto de la incorporación del poder y culto solar en la sociedad muisca. Dicho poder solar es encarnado en la figura masculina de Bochica. Aunque Correa encuentra en crónicas como las de Medrano que Bochica (dios solar) era hijo de Chía (diosa lunar), la narrativa generada e impuesta por el conjunto de producciones textuales de la Conquista y Colonia establecen tres momentos

1 El resaltado es nuestro. 
de la historia mitológica muisca marcados por puntos de giro en torno a las relaciones de los poderes cósmicos femeninos y masculinos.

En el primer momento, la sociedad muisca es gestada y educada en principio por la madre primordial Bachué. El segundo momento se presenta como una era de "civilización" y aprendizajes que llevaron al desarrollo de la sociedad y el poder solar. Por esta razón, Bochica -el cual también tiene nombres diferentes según el cronista que registró los mitos- se presenta como el dios "civilizador" de los muiscas. El tercer momento es el que pone en entredicho el rol moral de lo femenino, entre otras causas, por la visión patriarcal y machista propia de los cronistas de la época. Correa (2004) lo explica así:

Pero, salta a la vista que los cronistas convirtieron los relatos de la Madre Ancestral en un diatriba contra la mujer. La estigmatizaban por su hermosura, sensualidad, su dedicación al placer, y tergiversación de anteriores enseñanzas (la apostasía), que habría seducido a las gentes para confundir la doctrina sobre la resurrección y la inmortalidad del alma impartida por el padre (p. 52).

En la narrativa general de los cronistas, una vez Bochica impone la normatividad social y política de los muiscas, aparecen la figuras de Chía y Huitaca, diosas lunares, como retadoras del orden solar, razón por la cual Huitaca en particular es castigada por Bochica al ser transformada en lechuza. De esta manera, al igual que en la mitología judeocristiana, la mujer es estigmatizada como tentación que pone en peligro el orden moral y es condenada al mundo de la noche (lechuza) y de lo netamente terrenal. En esto último la serpiente, representación muisca positiva de la mujer primordial, adquiere cierta connotación similar a la del libro bíblico del Génesis.

Sin embargo el campo de producción narrativo estructurado por los cronistas también se torna un campo de disputas simbólicas por la reivindicación femenina. Esto ocurre cuando hemos logrado registrar en nuestro trabajo de campo múltiples reflexiones orales por parte de mujeres muiscas en las que Huitaca no cumple un papel estereotipado de la mujer sensual que tienta a los hombres a comportarse en contra 
del orden moral. Huitaca, en este caso, adquiere el rol del poder femenino que "confronta y pone a prueba", siendo este una fuerza que contribuye a medir la voluntad moral de la humanidad y no a contrarrestarla. Incluso hemos encontrado versiones orales actualizadas de dichas narrativas mitológicas en las que mientras Chía representa el lado luminoso y visible de la luna, Huitaca representa el lado oscuro e invisible del astro, con lo que nuevamente la dualidad sistemática se repite para dinamizar y complejizar el rol de lo femenino dictaminado por la cosmovisión muisca.

Tal dinamismo y complejidad encerrados en la dualidad luz-oscuridad (Chía-Huitaca) de lo femenino que a su vez alimenta la tensión entre lo femenino y lo masculino (poder lunar-poder solar) es clave a la hora de comprender las reivindicaciones del rol de la mujer en los procesos culturales y políticos contemporáneos de las comunidades muiscas. En el siguiente apartado veremos de qué manera las reinterpretaciones hechas a la narrativa mítica de los cronistas han generado nuevas versiones que integran la mirada mitológica con la mirada histórica para comprender la importancia de darle al poder femenino un lugar relevante en el presente.

\section{La matriz: memoria histórica de lo muisca}

De las reflexiones en torno a la cosmogonía muisca registrada por los cronistas españoles, pasemos al mundo cotidiano de las comunidades muiscas de hoy. En el marco de las actividades comunitarias en las que tuvimos la oportunidad de participar, varios hechos perceptibles y observables daban cuenta de la presencia del poder femenino y de las tensiones resultantes de su evidencia en ciertos momentos específicos. El "poder femenino" es lo que por ahora nombramos como un conjunto de campos de expresión en donde los temas, metáforas y reflexiones sobre los signos de la mujer hacen su aparición de múltiples maneras (protección, gastronomía, familia, sexualidad, siembra, etc.) y generan cambios, inciden de manera directa en procesos de transformación a nivel individual, colectivo y territorial. También veremos cómo ese poder femenino se relaciona de manera muy cercana con el poder de la curación. 
Figura 3. Círculo de palabra

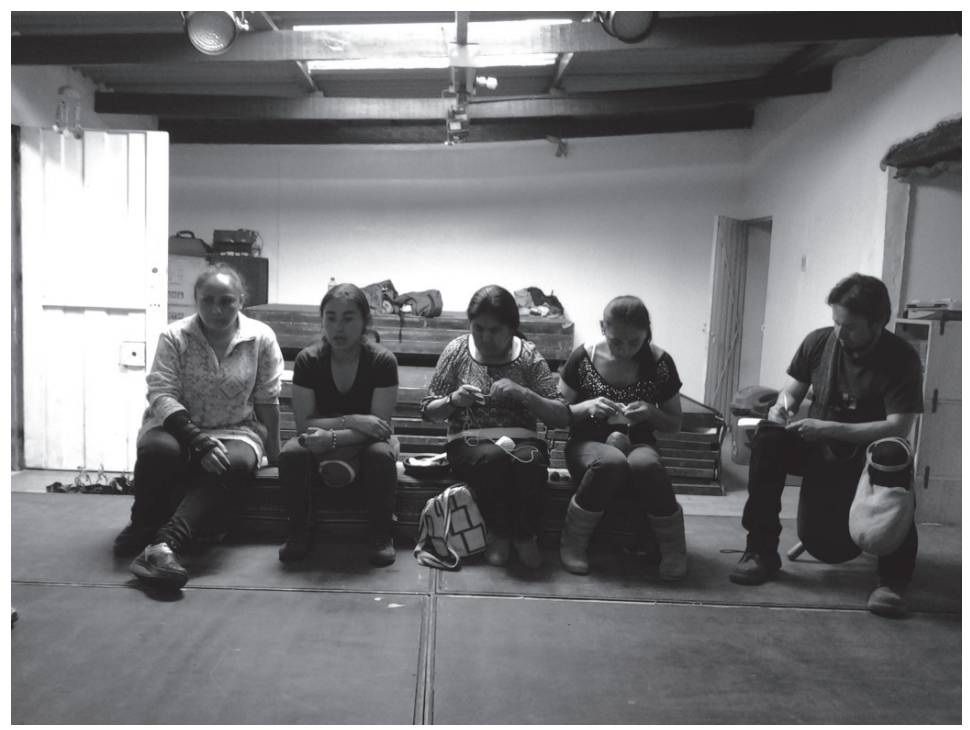

Fotografía de Pablo F. Gómez Montañez. Yilena y la abuela Cecilia lideran el círculo de palabra de las mujeres en la casa de medicina Zhue Gata. Mediante el tejido, las mujeres recogen los pensamientos y propósitos colectivos.

Figura 4. Poder femenino y masculino

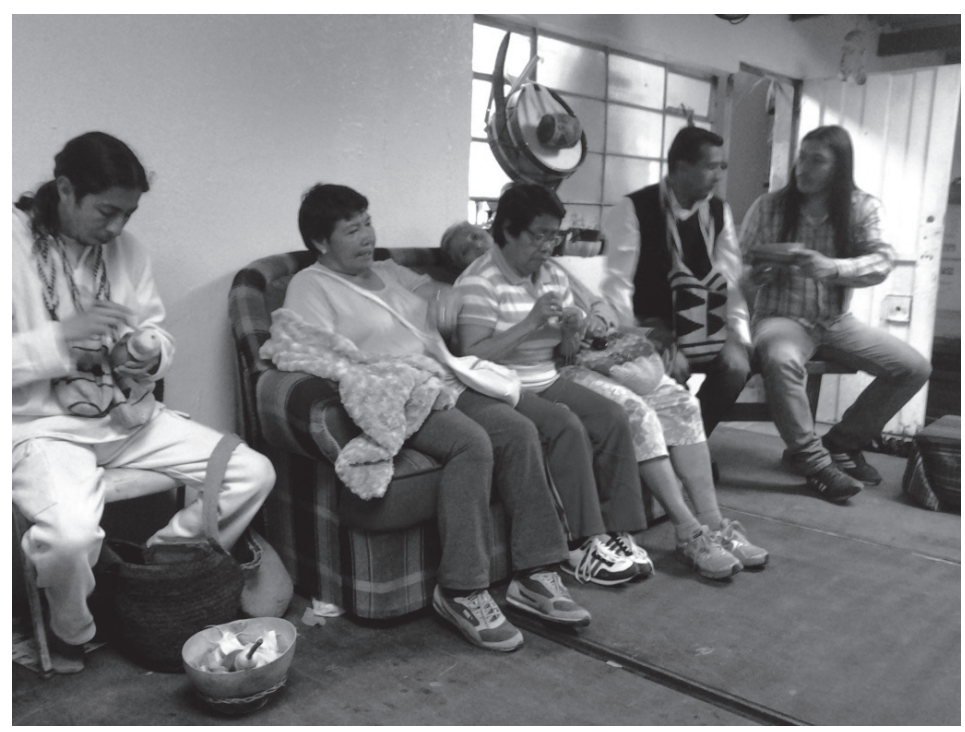

Fotografía de Pablo F. Gómez Montañez. Mayoras de Bosa comparten sus memorias de juventud mientras tejen. Se comparte chicha y John, líder de medicina, poporea. De esta manera el poder femenino (tejido) se complementa con el masculino (poporo). 
Como ejemplo, parte de los relatos de vida que registramos y analizamos en el capítulo anterior se llevaron a cabo en un encuentro liderado por mujeres muiscas en la casa de medicina Zhue Gata, cuya sede está ubicada en la plaza central de Bosa, cerca de la iglesia. Los elementos que resaltaremos a continuación para introducir la argumentación del apartado son tomados del diario de campo personal del investigador principal, fechado el 28 de julio de 2015 .

A diferencia de otros espacios de reunión-conversación, en esta ocasión no hubo repartición de medicina hecha con plantas como usualmente ocurre. La idea, incluso resaltada por los hombres líderes de medicina presentes, era que todo girara alrededor del alimento, el cual hace parte de los "transmisores de la fuerza femenina", que se materializa en el cuidado comunitario y la salud brindada por la nutrición. Cabe recordar que los muiscas en su agradecimiento a la Madre recuerdan y refuerzan el aporte energético-cósmico de la Tierra como figura materna y femenina que brinda los alimentos. Además, preparadas por las mujeres, la sopa, las papas y el aguacate conformaban en el plato de comida un objeto activador de las memorias orales que se compartieron en la reunión.

Además del alimento, ocurrió algo que pudimos registrar constantemente en otros espacios: el humor en relación con el sexo. Algunas mujeres "tomaban del pelo" al afirmar que la sopa era de "chisa", es decir del gusano de la papa. Edward, joven líder de medicina de Bosa, dijo jocosamente que la chisa era un "afrodisíaco muisca”. Incluso amplió su broma al señalar que una de las mujeres asistentes "ya había tomado de esa sopa y que ahora tenía ocho meses de embarazo”. Por supuesto, todos los asistentes reímos.

En medio de la "familiaridad" de la reunión, una totuma con chicha fue colocada en el centro de la tarima de madera donde los comensales estábamos sentados formando un círculo. Como es usual, la chicha fue preparada por mujeres y son ellas quienes la ofrecen a la Madre y la reparten a los participantes. Edward en su discurso resaltaba que la acción de "compartir" era propio de la "casita", elaborando una metáfora del hogar y la familia para definir el propósito del encuentro.

Además lo complementó con la metáfora del “tejido" para explicar la manera como en los procesos llevados a cabo se vinculaban 
los propósitos y aprendizajes de toda la comunidad. Yilena, quien se consolidó como mujer moderadora del encuentro, complementaba las palabras de Edward al recordar que una golondrina de agua había llegado cuando varias "mayoras" hacían un trabajo en la laguna de Chiguasuque, lo cual era un mensaje de aprobación de la Madre por el "amor" con el que se hacían las cosas. Al tiempo que se decían estas palabras, Yilena y varias mujeres tejían.

Finalmente, y antes de dar paso a los relatos compartidos por mujeres mayores de Bosa, Yilena recordó varias señales positivas que se recibieron de los espíritus del territorio cuando realizaron pagamentos en la laguna. La principal era que los espejos de agua, que antes estaban tapados por la acumulación de la planta llamada buchón, ahora estaban despejados. La razón, según Yilena, era el buen "trabajo" de pagamentos realizados por mujeres con flores amarillas que representan al sol y la abundancia. La presencia actual de flores amarillas al lado del humedal señalaba que "el espíritu del territorio los había recibido".

Gracias al pagamento se llevaban a cabo dos acciones conjuntas: en primer lugar, recuperar el nombre sagrado de la laguna, por lo cual Chiguasuque significa "semilla de alimentos". En segundo lugar, derivado de lo anterior, el pagamento canalizaría las fuerzas cósmicas de manera tal que dicha abundancia de semillas fuera posible. La relación semillas-abundancia con lo femenino se hacía evidente en los actos de habla de Yilena.

De esta manera, el poder femenino se hacía presente en varios elementos que conformaban una constelación-tejido de imágenes-fuerzas: tierra-alimento-sexo-tejido-totuma-chicha-compartir-círculoflores-amor-laguna-semillas-abundancia. Luego de tales introducciones, las mujeres mayores compartieron sus relatos de vida. Durante tales momentos, llegó a la reunión un líder fundador de la comunidad muisca de Ráquira: el abuelo Kulchavita. Lo interesante que sucedió cuando tomó la palabra fue que mientras las memorias de las mayores correspondían a hechos cotidianos y ligados a valores como el respeto a la familia, al trabajo y a las sanas costumbres de antaño (ver capítulo anterior), Kulchavita retomó simples anécdotas y las elevó a un plano más cercano a la memoria como ejercicio de profunda reflexividad y complejidad discursiva. 
Esto que resaltamos es importante, pues de manera reiterada hace parte de las fórmulas orales mediante las cuales varios líderes muiscas de hoy vinculan la indigenidad muisca, un discurso muchas veces cargado de lenguajes especializados del campo espiritual y mitológico, con las memorias más simples de la vida campesina de los padres y abuelos.

Kulchavita se conectó al "tejido" de Yilena al resaltar la importancia del rol femenino en lo muisca mediante el tropo de la "semilla del maíz”. El maíz es un elemento fundamental de las culturas indígenas de América que adquiere particular relevancia en nuestro caso por la metáfora que Kulchavita construye para explicar la resistencia y permanencia del pueblo muisca contemporáneo.

Como es una tendencia detectada en la discursividad muisca actual, Kulchavita comenzó su palabra afirmado que el "despertar muisca”, término con el que varios se refieren al proceso de reetnicidad, era una realidad que podía verse hoy, que "el tiempo había llegado". A manera de una profecía que se cumplía, Kulchavita afirmaba que el muisca existía pese a la incredulidad de los antropólogos y la academia en general. Lo clave fue la manera como elaboró la metáfora con la semilla del maíz para explicarlo y la relación de cada componente con el poder femenino.

El primer componente es la "tierra”, el sostén de todo y de la planta en particular. El tropo sugiere que el pueblo muisca ha mantenido sus raíces y que se ha aferrado fuerte a la tierra para existir, sobrellevando cualquier obstáculo. El segundo componente es el "agua”, elemento femenino que "mueve la memoria y ablanda la tierra y la semilla". Es el tropo de la "activación de la memoria" que permaneció. El tercero el rol —aparentemente masculino— del sol y el calor para permitir que la semilla "brote". Si bien es una metáfora de la fertilización y de la dualidad, masculino-femenino, Kulchavita resalta el poder de la mujer al relacionar el calor con los "afectos" y las "pasiones” necesarios para que la memoria continúe fluyendo y brotando. El cuarto componente es el aire, por el cual la planta, una vez que germina, "camina y sube" para hacerse fuerte. Ese fue el tropo de la memoria muisca: una memoria que, como semilla del maíz, no desapareció sino que permaneció y fue cuidada y activada por el poder de lo femenino. Por supuesto, el modelo se puede terminar de explicar con la emergencia de 
flores, frutos y semillas que volverán a la tierra para comenzar el ciclo de revitalización-memoria-despertar.

Figura 5. El ciclo del maíz en relación con el poder femenino

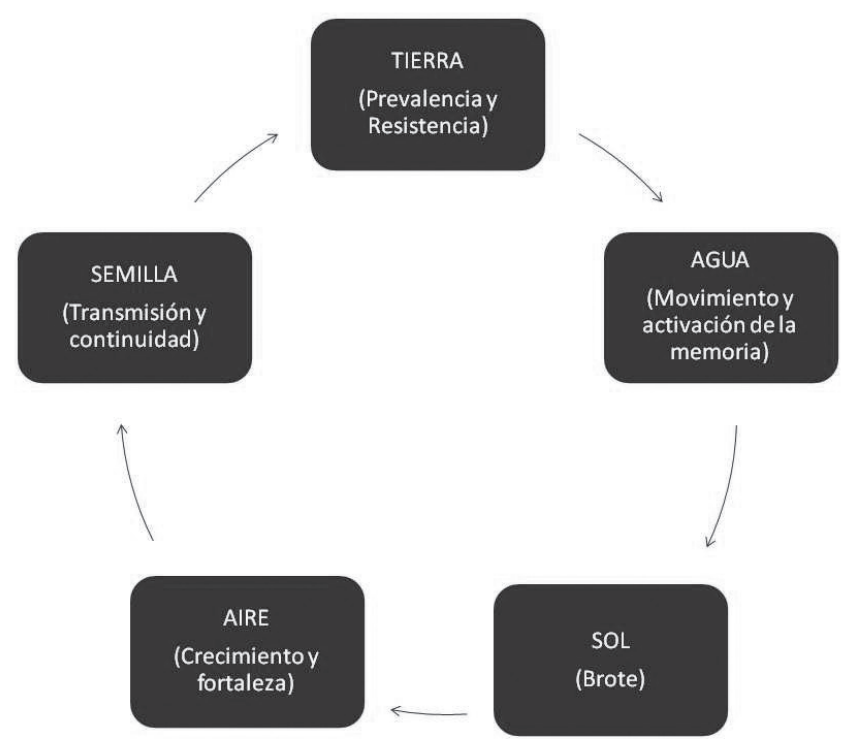

A continuación, Kulchavita elaboró una conexión con los mitos explicados anteriormente, con lo cual comenzó a reivindicar el rol de la mujer. Según él, fue Bagué, la diosa Madre, y no Chiminigagua, dios Padre, quien "materializó lo que venía", es decir, la creación del cosmos y de la gente, de los "muiscas". Seguidamente, Bachué fue definida como “madre y espíritu de lo femenino". De esta manera se proponían nuevas formas de reforzar la dualidad y la complementariedad, así como la relevancia de la mujer en los procesos de memoria indígena muisca.

Lo que hay que recordar es que el orden está en la casa, por eso Bachué hizo la casa con Fuchunsúa, ellos dijeron que la clave estaba en el orden de la casa, y la casa es la posibilidad para recuperar todo, y ordenar todo en pareja, y la clave está en la pareja que se ordena dentro de la casa, entonces hay que entender que la casa es el orden, el camino, o sea la casa contiene un camino del origen: el camino de Chiminigagua. Entonces la clave está en el orden y 
ahora se está restableciendo ese orden. Como la memoria está ahí, solo se necesita agua y calor para que se dispare la memoria, o sea que es posible que haya que cantar y haya que danzar para que se despierte, porque danzando y cantando se produce calor y ese calor entonces dispara la memoria y la semilla (Abuelo Kulchavita, comunicación personal, julio 28 de 2015).

Como se profundizó en el capítulo anterior, la "casa" el primer territorio comunitario, contiene las fuerzas femenina y masculina que ordena socialmente el mundo. Chiminigagua, deidad masculina, establece su camino mientras haga parte de la fuerza de la mujer de la casa. Además, el canto, el soplo de aire, es la fuerza que despierta la memoria, pues en palabras de Kulchavita, "[...] es tiempo de despertar la memoria de la semilla en todo el territorio, danzando y cantando".

Consecuentemente, esto explica la presencia de cánticos en la renovada lengua muisca, compuesta en su mayoría de onomatopeyas y palabras sueltas que se entrelazan mediante frases musicales repetitivas a las que se les han otorgado significados complejos. Sin embargo, para los muiscas de hoy tales rutinas y repertorios no corresponden a invenciones creativas, sino a ejercicios de reactivación de una memoria que permanece. Para Kulchavita, los “abuelos” ordenan que se debe "cuidar esa semilla, cuidarla bien y cantarle bien, y así como dicen los abuelos esa semilla nace aprendida, ya nace sabiendo, porque todo está ahí en la semilla”. Con la metáfora memoria-semilla que nace aprendida, Kulchavita reivindicaba el rol femenino, argumento que, por supuesto, fue aprobado positivamente por los asistentes a la emotiva y familiar reunión en la casa de medicina.

\section{El dolor de la mujer: los tropos de la dificultad de la memoria}

Una vez se comprende el rol de lo femenino en el despertar de la memoria muisca, debe entenderse que tal misión conlleva dolor y sufrimiento, no solo por el reto a futuro, sino por las cargas históricas que implica. Por esa razón, la "contaminación”, el “dolor”, el "maltrato" 
y el "sacrificio" emergen como tropos que explican tanto las vejaciones sufridas por las mujeres indígenas en el proceso de Conquista y Colonia, como los indicadores de éxito que tuvo el poder femenino en mantener la existencia del pueblo muisca.

Estamos entendiendo que en este proceso de rehumanización es vital reafirmar el espíritu del territorio muisca que es el espíritu de Bachué, y recomponer ese espíritu y esa experiencia de la feminización, el papel de la mujer, el papel de lo femenino porque es lo que sostiene la existencia y es la que guarda la memoria y la tradición. Si esta sociedad no resuelve esto no hay posibilidades porque ella es la que cuida la semilla y alimenta la semilla. Por eso esta tradición habla tanto de Bachué, por eso se dice que ese trabajo es fuerte porque hay que limpiar las aguas contaminadas, hay historias de dolor y de maltrato porque ellas entregaron a sus hijos, el espíritu de servir a sus hijos y eso fue lo que sostuvo a la humanidad, la gente, ellas se sacrificaron por sus hijos, pero aguantaron (Kulchavita, comunicación personal, julio 28 de 2015).

Todos los componentes del poder femenino identificados en este apartado se vinculan en un solo tropo: el de la matriz. La matriz resguarda, da vida, alimenta y es el primer territorio. También protege, resguarda y mantiene aquello que surgirá cuando llegue su tiempo; es dadora de vida. Es el elemento que define a la mujer y, consecuentemente, la fuente de su poder. Por esa misma razón, la matriz es objeto de dolor y sufrimiento.

Los indígenas de América interpretan su memoria histórica como una narrativa que implicó la "violación” de la mujer nativa por parte del europeo, lo que le dio paso a un mestizaje "a la brava". Como botín de guerra, la mujer no solo fue violentada como acto de conquista, sino como portadora de la memoria. Tal interpretación lleva a Kulchavita y a otros líderes a emplear la metáfora de la "olla de barro" como la matriz en la que la mujer muisca guardó la memoria en la "semilla del blanco". Más que recordar el acto de la violación, Kulchavita prefiere comprender la invasión de la matriz muisca por parte de la semilla 
del conquistador como acto estratégico de resistencia, pues haría parte de una frase típica y profética que explica el despertar muisca en medio de la vida moderna: "el muisca renace en el rostro del enemigo".

Eso explicaría la manera en que la indigenidad se produce en el marco de individuos y grupos sociales que a primera vista se catalogarían como "mestizos", "blancos" o sencillamente "urbanos" y "modernos". La presencia de rasgos "no indígenas" indicaría no la desaparición sino la permanencia estratégica y mimetizada del pueblo muisca en la semilla de caucásico europeo. Sin embargo, ese dolor histórico debe ser "limpiado" y "curado" como parte del despertar, de ahí la prevalencia de escenarios medicinales-espirituales en el marco de procesos de reivindicación étnica muisca en la actualidad.

Hay una historia, ese maltrato, ese sentirse que no fueron bien tratadas se fue transmitiendo generación tras generación. Entonces dice el abuelo que hay que limpiar esa historia, limpiar ese camino, limpiar esas aguas para librarnos de esa memoria de maltrato que hay ahí, de congojo que hay ahí para que eso no le llegue a la semilla, hay que limpiar el agua de la totuma, y eso es pues una terapia que hay que hacer (Kulchavita, comunicación personal, julio 28 de 2015).

De esta manera no solo se reafirma la relación femenino-matriz, sino además la existente - y necesaria - entre la revitalización de la identidad indígena, la memoria y la medicina: parece que el proceso de recordar y tener conciencia de las raíces implica curar y limpiar un dolor histórico y moral. El mestizo o "blanco" de hoy es la figuración de una semilla indígena que se mimetizó para resistir y germinar gracias al poder femenino: "La semilla caminará para ser mata de maíz, mazorca y maizal", es la palabra contundente final de Kulchavita en su intervención. En ella se resume el rol de la mujer como guardiana y activadora de la memoria muisca. Por eso son reiterativas las frases en las que se invita a "limpiar" la matriz, a limpiar el linaje, pues sanar el útero materno y sus extensiones — todos los componentes femeninos analizados hasta ahora- garantiza la salud comunitaria y la reproducción social como grupo. 
En el marco del rescate de la lengua muisca hoy, los líderes se refieren al Tamuy, es decir, el origen del "ser gente", lugar donde el cielo se enamora de la tierra, del páramo. Así, la dualidad y complementariedad de lo femenino y masculino se reafirma como condición necesaria para el fortalecimiento de la cultura muisca. Tal discurso complejo se materializa cotidianamente en rutinas y repertorios que se dan en medio de diversas ceremonias llevadas a cabo por grupos muiscas practicantes de la medicina. En dichos escenarios se canaliza el dolor y el sufrimiento de la mujer para convertirlo en la medicina más poderosa que existe.

\section{La canalización del dolor y el sufrimiento: la medicina de la mujer}

Mujeres Bachué es el nombre de un colectivo de mujeres de Bogotá, indígenas y no indígenas, que tiene como misión promover el rol de la familia como núcleo de una "crianza respetuosa". Al ingresar a la sede ubicada en la calle 52 con carrera 16, dos obras pictóricas llaman la atención. La primera fue hecha por el pintor Daniel Molina y representa a una mujer de rasgos indígenas con una corona de olivos, similar a la estatua de la Libertad en Nueva York, y se titula "Libertad, Fuerza Femenina". La segunda no tiene firma de autor y muestra a una mujer embarazada cargando un niño en sus brazos. El fondo es verde, muy vistoso, y la mujer es acompañada por las figuras del sol y un colibrí. El colectivo es liderado por Ramiro, miembro de la comunidad muisca de Cota, partero de oficio. Yuli Chiguasuque, mujer de la comunidad de Bosa, a quien Ramiro ayudó en su labor de parto recientemente, lidera el encuentro que programamos para dialogar con mujeres muiscas y bogotanas sobre el tema de la familia.

Cuando se habla sobre la partería natural y tradicional, es usual que surja el tema del manejo del dolor de la madre al dar luz a su hijo y durante la menstruación. Desde el primer momento del diálogo, Yuli no dudó en afirmar que el dolor del periodo es un "guion occidental" y que en la cultura muisca dicho dolor se vuelve "medicina", pues se interpreta como una manera de "entregar la luna". "Luna” es el término 
para designar la menstruación, debido a su duración promedio de 28 días y sus cuatro fases - nueva, creciente, llena y menguante-, siendo la primera la renovación de la matriz, la segunda y tercera los periodos de fertilidad y la última la de sangrado y "limpieza".

$\mathrm{Al}$ igual que en otras culturas, la menstruación implica tabúes. El no acercarse al fuego ni prenderlo durante ceremonias por parte de la mujer menstruante es el más habitual en los muiscas de hoy. También puede prohibirse a la mujer menstruante preparar alimentos. A diferencia de otras comunidades, para las mujeres muiscas la menstruación es un canal de limpieza y curación, ya que con la renovación de la matriz se sanan varios procesos y elementos individuales, familiares, comunitarios y territoriales. Debido a eso, en algunos grupos las mujeres en luna pueden manejar el fuego y la cocina sin tabú.

La matriz de la mujer, entonces, es un elemento medicinal importante. Parte de su poder está en el control o canalización del dolor y el sufrimiento. Yuli recordaba el parto natural de su hija en casa. En lugar de permanecer acostada, con anestesia y medicamentos que en un hospital ayudan a dilatar la vagina como el Pitocin, Yuli tenía que batir una olla de masato durante sus contracciones. En lo aprendido de su partero Ramiro, como madre debía "meditar las contracciones", es decir, colocar "propósitos” y concentrarse en las virtudes que serían transmitidas a su hija al nacer. Dichos repertorios hacen parte de las prácticas de parto natural del colectivo Mujeres Bachué.

Vale recalcar que Yuli es una mujer muy joven, no debe pasar de los 25 años. Este dato resulta importante, pues aunque la partería descrita suele reivindicarse como una práctica "rescatada" de las tradiciones antiguas de las abuelas indígenas y campesinas, mujeres de generaciones anteriores crecieron con tabúes frente a este tipo de parto. Es el caso de Cecilia Chiguasuque, treinta años mayor que Yuli aproximadamente. Contrario a lo que se pensaría de una mujer de origen campesino, a Cecilia "le dio cosa" ver nacer a uno de sus hermanos. Verlos nacer era tabú en su familia, por lo cual su padre la "sacaba" y en una ocasión hasta "le dieron garrotera por chismosa". Aun así, recuerda al parto tradicional con una frase sencilla pero diciente: "mamá colgada y salió el chino". 
Otra mujer interlocutora en casa de Cecilia durante su relato recordaba que algunas mamás tenían a sus hijos solas y que para ello se dirigían a una laguna o quebrada, lo que se relaciona con prácticas registradas por cronistas de antaño sobre los muiscas. Con tal aporte, la interlocutora resaltó nuevamente que "antes todo era más sano y limpio", con lo cual también vinculaba las propiedades de limpieza del agua con la naturalidad y sanidad del parto. Como es de esperarse, el mismo marco interpretativo permitió que Cecilia hiciera un contraste con la maternidad moderna, caracterizada según ella como algo desordenada y descuidada. Uno de los indicadores de esto para Cecilia era que "ahora las mujeres no se cuidan ni hacen la dieta", mediante la cual las mujeres de antes garantizaban un parto más saludable en armonía con la sanidad del entorno campesino.

Cecilia recordó que a las mujeres embarazadas les daban de comer gallina y chocolate de siete granos. Tal dieta era reservada exclusivamente para la futura madre. La práctica más común era que la madre guardara reposo y una dieta especial durante los cuarenta y cinco días posteriores al parto, pues durante ese tiempo era cuando "la matriz daba la vuelta, si no se bajaba la vejiga". La alimentación de la madre consistía en "mazamorrita" y "candil", bebida hecha con leche y huevo diferente a la "changua".

De esta manera, y a partir de los datos biográficos brindados por las mujeres en torno a la menstruación y al parto, las interlocutoras coincidían en diferenciar la maternidad contemporánea como llena de "dolor". Para Yuli, dicha situación es fruto de la imposición del pensamiento católico, quien "condenó" bíblicamente a la mujer a parir con sufrimiento. Pero para estas mujeres el punto clave no es la simple evitación del dolor en los partos modernos, sino el hecho de que la madre no sea consciente de que su capacidad de canalizar la energía de la matriz y la fertilidad es un don muy poderoso que, aprendido a usar, le permite a la mujer potenciar su rol curador, ordenador y protector en la familia y la comunidad.

De esta manera, en los repertorios ceremoniales relacionados con los pagamentos y curaciones de hoy es normal encontrar el trabajo dual y complementario de la medicina femenina y la masculina. A continuación nos detendremos a analizar cómo se da dicha complementariedad 
por parte de quienes guían las ceremonias de sanación territorial, tema que ya había sido abordado en una investigación anterior sobre el rol curador del territorio en los procesos de memoria muisca (Gómez, 2016).

El primero de julio de 2015 un grupo conformado por miembros de la casa de medicina Zhue Gata e investigadores de la Universidad Santo Tomás se dirigió al humedal Chiguasuque en Bosa. Guiados por Myriam Martínez Triviño, mujer indígena de Suba y agrónoma, el objetivo inicial era instalar unas barricadas con palos de madera que protegieran un sector aledaño al cuerpo de agua. La imposibilidad de ingresar al humedal debido a la no permisividad del vigilante, hizo que el grupo optara por ubicarse en la orilla del camino destapado aledaño al lugar y realizar un pagamento, como se le denomina a nivel general a ceremonias y repertorios cargados de espiritualidad y medicina que tienen el fin de "limpiar" a las personas en conjunción con el territorio.

Este pagamento hizo parte de un conjunto más amplio al que ya nos referimos mediante las reflexiones de Yilena en el encuentro liderado por mujeres. Para "despertar el espíritu de la semilla”, acorde con el significado del topónimo Chiguasuque, la abuela Cecilia sirvió chicha en una totuma y mediante ademanes y venias la ofreció al territorio, derramando un poco sobre el suelo. La chicha se prepara mediante una "matriz", es decir, un residuo de la bebida que ya está fermentado y que garantiza la continuidad de dicho fermento. Pero nótese que claramente representa el útero de la mujer y el rol de brindar alimento que suele ser otorgado a lo femenino en las culturas indígenas. Vincula nuevamente la figura de la semilla del maíz como objeto contenedor de la memoria indígena vista en un apartado anterior.

La relación totuma-matriz-chicha-mujer se hace evidente no solo en la ceremonialidad sino que se legitima en aspectos más banales y cotidianos como el humor. Cuando John Orobajo, quien como hombre de medicina lideraba el pagamento y aportaba el "poder masculino" probó la chicha, dijo: "esta chicha está como usted abuela, picosa". Todos soltaron carcajadas, con lo cual el chiste evidenciaba las conexiones de la preparación de la chicha con las características de la sexualidad de la mujer preparadora. Sin embargo, lo importante del dato es la manera como en la cotidianidad se relaciona el fermento del maíz con la "energía” de la abuela. John continuó elaborando conexiones y relaciones 
entre la comida y la energía humana al afirmar que, por ejemplo, "cuando alguien cocina sin condimentos es porque tiene una vida sin sabor".

De esta manera se evidencia la canalización de la energía de las personas mediante la preparación del alimento y de la presencia de la energía sexual, proveniente de la matriz femenina, en la chicha. Mientras que la "matriz" en contextos de la menstruación y el parto se relaciona con el dolor, ahora lo hace con la "dulzura" y el "amor" presentes y transmitidos en el alimento. Lo que se mantiene como elemento común, es la capacidad "sanadora" de la matriz femenina.

Esta cadena de significados y potencias asignados a la sexualidad femenina fue reiterada cuando Myriam sacó de su mochila un totumo pequeño que contenía ambil, es decir, gelatina de tabaco que se chupa. Cuando Cecilia probó un poco, dijo jocosamente de nuevo: "el poporo está suavecito". Las risas se presentaron nuevamente. Myriam respondió: "suavecito como yo", lo que aumentó la atmósfera humorística del grupo. Luego, de manera muy contundente, Myriam afirmó que el poporo o totumo era su "ovario".

Del humor pasamos a tonos más serios y acordes con la reflexión espiritual propia de este tipo de ceremonias. John contaba que gracias a los trabajos de "limpia" en el territorio, el río Tunjuelo "ya no olía tan sucio". La "suciedad", en el discurso de John, era indicador no de simple contaminación ambiental. Más bien significaba que "detrás de eso (la suciedad) hay una memoria que alimentar espiritualmente", con lo cual la suciedad es enfermedad y a la vez olvido en el marco de la memoria muisca contemporánea como ya lo hemos analizado. El rol de lo femenino fue resaltado cuando John relacionó la pérdida de la memoria muisca con el fin de lo que denominó "matriarcado", pues "eso rompió el equilibrio". "Matriarcado" en este caso no corresponde a su significado verdadero, que sería el del sistema de gobierno comandado por mujeres, sino a uno aceptado de manera flexible para significar el rol femenino en la cultura muisca. John se refería más bien a la "matrilinealidad", es decir, la transmisión del linaje por vía materna, aunque le añadía el componente del "poder femenino" presente en la capacidad sanadora de la mujer como extensión de la Madre y la Tierra.

Por la razón anterior, para John eran muy importantes los rituales de limpieza con base en el poder femenino, pues según él permitían 
recuperar el equilibrio en la relación mujer-tierra-vida. También recordó que durante el proceso de resignificación de lugares sagrados de Bosa $^{2}$, el mamo Ramón Gil, líder espiritual de los wiwas de la Sierra Nevada de Santa Marta, concibió al humedal Chiguasuque como "fertilidad de la vida" y que por esa razón eran las mujeres quienes debían manejar su "orden” y "abrir" el lugar. Sin el poder femenino, entonces, la memoria de este territorio no despertaría y, por tanto, la comunidad ni se curaría ni recordaría.

Gracias a las explicaciones de John, comprendimos que Cecilia y Myriam eran en ese momento "mujeres-puente", es decir, las canalizadoras de las energías y potencias sanadoras del territorio que permitían mediante su poder femenino — como abuela y sabedora de medicinadespertar su memoria. Ambas prendieron tabaco y una vela blanca. John alistó la josca, medicina de tabaco en polvo. Cecilia tomó el totumo con la medicina de John y la sopló con humo de su tabaco, con lo que la impregnó con su aliento, con su energía sanadora femenina. Además fue Cecilia quien "rezó” el tabaco, es decir, le colocó propósitos sanadores mediante las palabras que susurró al totumo. Mientras Myriam "rapeaba” (fumaba) su tabaco, Cecilia se acercó al líder del grupo investigador y le sopló la medicina en ambas fosas nasales hasta hacerlo toser. Continuó así desplazándose al contrario de las manecillas del reloj hasta darle la medicina a todo el grupo.

Al ritmo de armónicas, flautas y maracas tocadas por varios integrantes del grupo, John cantaba y en sus frases continuaba resaltando e invocando el poder femenino al encadenar varias imágenes: mujer-corazón moreno-jaguar-águila-vientre gestando al sol-mujer venado- tierra-mar-montaña-arena-geografía de mujer. Era tan importante resaltar el rol de la mujer y el poder femenino en la ceremonia, que incluso escuchamos cantar un soneto que ya habíamos escuchado en ceremonias de la comunidad de Sesquilé. La diferencia era que mientras en Sesquilé el canto era dedicado al Padre, en Bosa sonaba así: "Madre te siento bajo mis pies, siento los latidos de tu corazón".

2 Para comprender lo que significa "re-significación de lugares sagrados”, recomendamos revisar el libro, resultado de investigación, editado por Gómez (2015). 
Cecilia volvió a soplar la josca al grupo entero, y como registramos en otra investigación (Gómez, 2015), mientras la primera soplada fue para "limpiar" el cuerpo-comunidad-territorio esta segunda era para “agradecer" los dones recibidos por la Madre y el Padre creadores.

Para finalizar la ceremonia, John le dio flores de tijiquí (borrachero) amarillas a todas las mujeres asistentes y les indicó cómo "entregarlas" a la laguna. Esto hacía parte de la aplicación del "trabajo" de las mujeres ya referenciado por Yilena al comienzo de este capítulo. Mediante estas rutinas, entonces, el poder de la mujer, centrado en su matriz como espacio de gestación, protección y ordenación, canaliza la energía sanadora de su sexualidad. Para ello, el dolor y sufrimiento, relacionados con la menstruación — fases lunares- y el parto ahora se transformaba en poder curativo que se conjugaba con el de los hombres de medicina de manera complementaria. Pero antes de comprender cómo se da ese poder femenino, tan nombrado a lo largo de este capítulo, en prácticas específicas de medicina comunitaria, es necesario revisar la reflexividad de las mujeres muiscas respecto al fenómeno de machismo y violencia de género en sus comunidades.

Figura 6. Pagamento

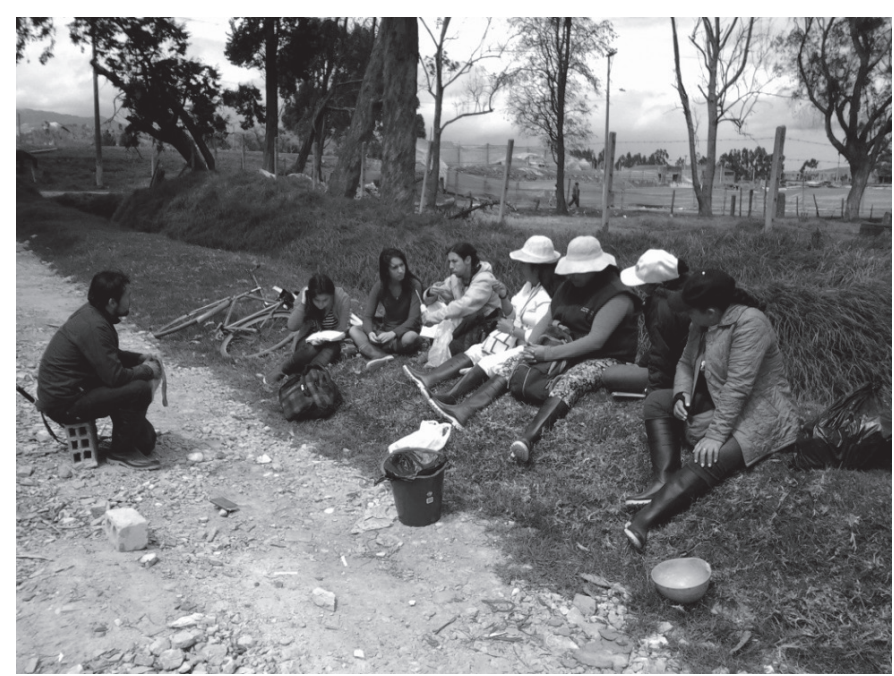

Fotografía de Pablo F. Gómez Montañez. Pagamento cercano al humedal Chiguasuque en Bosa, liderado por John Orobajo, líder de medicina. Participan estudiantes integrantes del semillero de investigación Aba Ye. 
Figura 7. Sanadoras del territorio

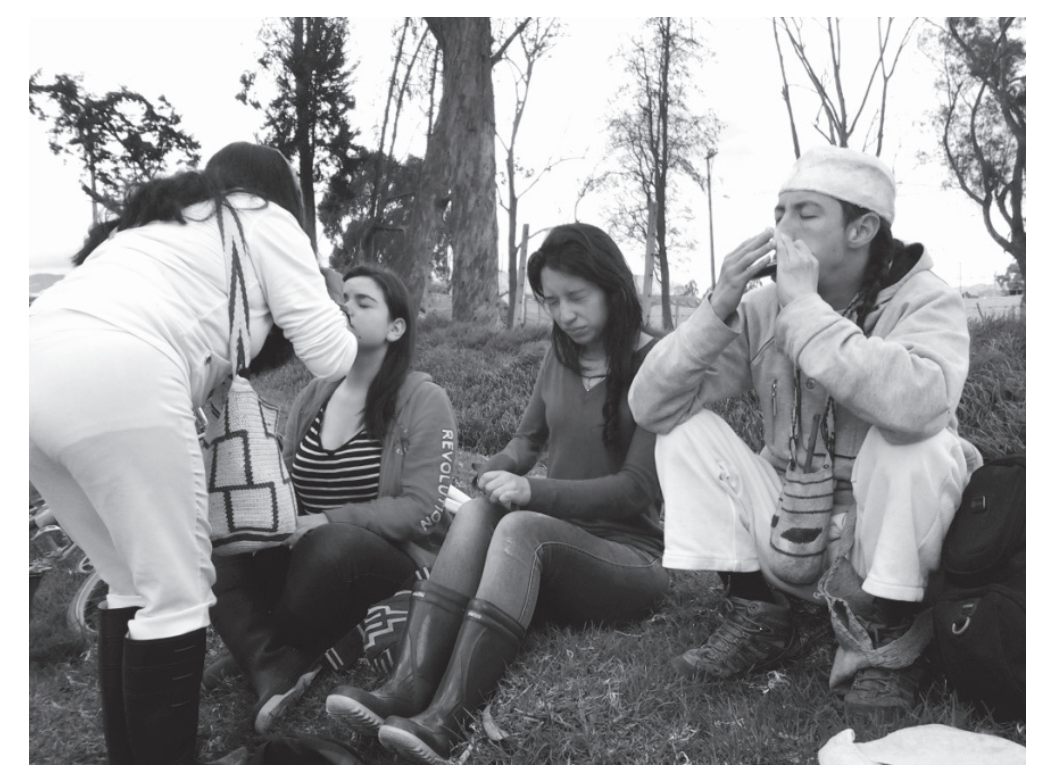

Fotografía de Pablo F. Gómez Montañez. La abuela Cecilia sopla la josca, medicina de tabaco en polvo. John armoniza mediante la música de dulzaina. Esta medicina pone "en armonía" a los participantes y los "enfoca" en el propósito curativo colectivo de ese momento.

Figura 8. La música, complemento del pagamento

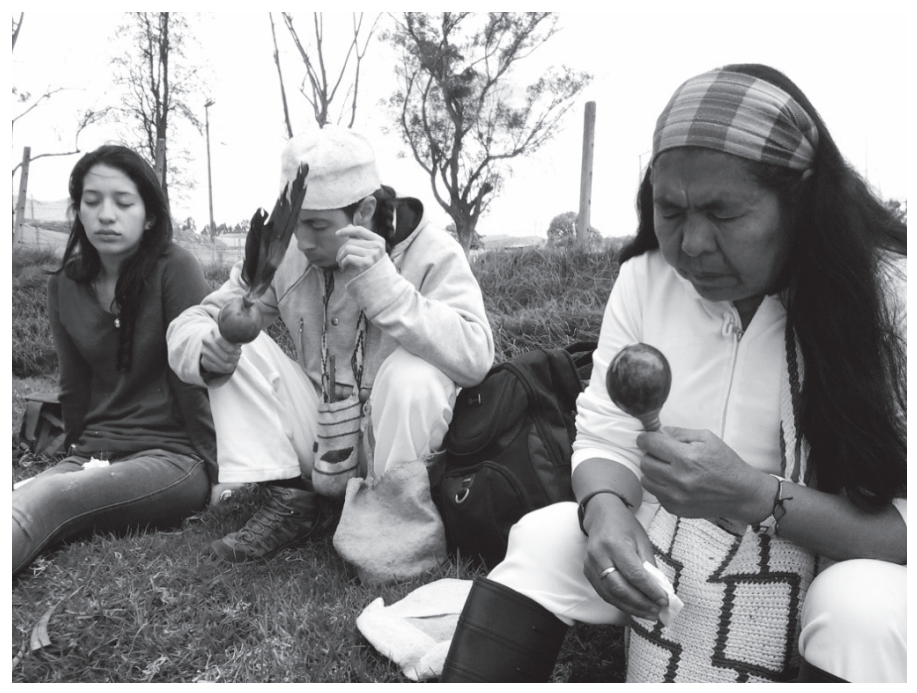

Fotografía de Pablo F. Gómez Montañez. Mediante la música se complementan y armonizan los poderes curativos masculinos y femeninos. 


\section{Revisiones históricas en torno al machismo en las comunidades muiscas}

La siguiente cita extensa del relato de vida de Cecilia Chiguasuque de Bosa nos hace retornar a un campo social y cultural que coloca a la mujer en una posición nada privilegiada y como objeto de varios tipos de violencia en la cotidianidad comunitaria, por lo menos de antaño.

[...] los hombres eran muy machistas, era como cuando éramos campesinos, porque los hombres eran muy machistas. El hombre no podía entrar a la cocina, los mismos padres le decían a una: 'los hombres en la cocina huelen a ralea de gallina, los hombres son pa' trabajar. Y mi papá era muy machista, decía: 'A los hombres es a los únicos a los que se les puede dar estudio, las mujeres son solamente para cocinar y tener hijos'. Y yo a mi papá me le rebele por eso: 'yo no me voy a quedar cocinando, yo sí voy a estudiar'. Y yo estudié. Pero ellos escasamente le daban a uno para que supiera leer y escribir, eso era todo, para defenderse en la vida. Pero de ahí nada más, en cambio a los hijos sí les daban el bachillerato. Y ahí también viene ese machismo y la mujer era lo que el marido dijera. Si decía: 'se queda ahí sentada hasta que yo vaya al pueblo y vuelva', ella tenía que quedarse allí. 'No, que yo no me puedo mover porque donde venga su papá me acaba'. Y si la encontraba eso la cogía solo a golpes. Entonces eso era el terror. Para nosotros el terror era el día domingo cuando ellos se iban pal pueblo, ellos sí tomaban mucho. Entonces cuando llegaban a la casa, llegaban borrachos, entonces ahí mismo por cualquier cosa tome su pela. Eso las cogían y las arrastraban, como en ese tiempo pasaban las zanjas de lado y lado, eso las agarraban del cabello y allá las mandaban al río. Y uno les decía: ‘ ¿y usted por qué se deja pegar?’, ‘¿no ve que él es el que manda?’. Y un día mi papá fue a pegarle a mi mamá y yo me le abroché al hombro: 'sumercé no tiene por qué volverle a pegar a mi mamá'. Y ya nosotros crecimos y la defendíamos mucho. Entre todos nos le arrimábamos, pero no le dejábamos pegar. Entonces para él eso fue terrible. Y 
eso era normal en comunidad, usted encontraba una vecina con el ojo negro, a la otra le estaba pasando y ya le comenzaba el otro, y se la pasaba así (Cecilia Chiguasuque, comunicación personal, septiembre 5 de 2015).

Aunque en un apartado anterior hemos afirmado que mediante el alimento se transmite la "fuerza femenina" que protege al grupo social, algunas mujeres muiscas de hoy ven la cocina como un espacio de sumisión ante el hombre cuando su permanencia en este y su uso no son voluntarios, sino resultado de restringidos roles de género. Sumado a eso, en la actualidad las mujeres indígenas, más aún cuando sus comunidades han sido influenciadas por los estilos de vida urbanos y modernos, ven en el acceso a la educación formal avanzada una oportunidad de emancipación. La "rebeldía” de Cecilia ante su padre se basó, entonces, en querer salir de la cocina e ingresar al mundo educativo que en su momento era reservado a los hombres de la casa. Como es de esperarse, el relato de Cecilia es representativo de aquellas prácticas machistas que terminan por hacerse presentes en el cuerpo de la mujer como objeto de violencia directa, que termina siendo "incorporada" y, por tanto, naturalizada por las mismas mujeres en su momento. ${ }^{3}$

El contenido del relato también se vuelve representativo de otra reflexión y pregunta predominante en diferentes grupos y redes de la reetnicidad indígena general y muisca en particular: ¿Cuál fue el origen de tal violencia en las comunidades indígenas? Ya vimos que para Kulchavita la violencia contra la mujer es reflejo de la enfermedad y el desorden que hoy día se busca curar para garantizar el despertar muisca. Lo usual en los momentos de reflexión histórica de largo aliento en las comunidades es otorgarle la causa de ciertas prácticas sociales negativas al proceso de Conquista y Colonización europea.

Sin embargo, la madurez de algunos procesos particulares de reflexión histórica en grupos específicos como el de la casa de medicina Zhue Gata, revisan críticamente tal afirmación radical y típica de los

3 Sobre la relación entre la "violencia sobre el cuerpo" y la "violencia incorporada”, ver el análisis teórico de Chaves (2011). 
actuales movimientos de reivindicación étnica y crítica colonial. El discurso predominante en tales radicalismos aseguraría que la incorporación de la violencia hacia la mujer presente en el relato de Cecilia es netamente influencia del "patriarcado español". Sin embargo, Yilena aporta una categoría que confronta tal argumento: el "patriarcado ancestral”.

\begin{abstract}
Ahí hay varios factores. Uno, y tiene que ver mucho con la razón por la que de cierta forma el español llegó aquí e hizo su proceso invasivo, colonizador, y era porque los pueblos indígenas se empezaron a desordenar en ese sentido, las comunidades indígenas comenzaron a desordenarse y empezó a generarse lo que en algunas concepciones feministas se llama el 'patriarcado ancestral'. Esta es una categoría como importante. Y unas feministas indígenas están poniendo ese tema. Porque qué pasa, hay algunas comunidades indígenas, y lo digo también por experiencia, con las que yo he podido compartir, hay algunas que dicen que el machismo llegó con los españoles, eso es una mentira, ya existía, por eso hubo un desorden en el territorio y por eso digo yo la invasión. La invasión fue una causa-efecto del desorden que ya había. Y por eso fue tan violento también. Entonces eso suma un primer factor. Se suma el patriarcado que trajo la conquista española. Ellos mismos dentro de su religión y de su ideología la mujer tampoco hacía labores considerables y eso se fue acomodando aquí con las costumbres, de una u otra forma la Iglesia también causó eso (Yilena, comunicación personal, septiembre 5 de 2015).
\end{abstract}

La reflexión de Yilena vincula dos factores de la violencia de género en las comunidades indígenas: el patriarcado ancestral, con el cual el poder político y social se incorporó tajantemente en los hombres, y el patriarcado europeo que, según ella, encontró una base cultural muy compatible en el primero. Según esta revisión histórica de algunas "feministas indígenas", el machismo indígena no es resultado de la imposición colonial, sino de la armonización y complementariedad de dos visiones culturales que valoraban el poder masculino sobre el femenino. 


\section{Restaurar el equilibrio: la reivindicación del poder femenino}

Sea cual sea la causa aceptada del machismo en las comunidades indígenas, lo cierto es que cuando los procesos de revitalización étnica son alimentados por el rescate de discursos y prácticas medicinalesespirituales, el "despertar muisca" exige la reivindicación de las figuras femeninas (diosas como Bagué, Bachué, Chía y Huitaca y roles de poder como cacicas, furas y sacerdotisas) y la complementariedad de las fuerzas femeninas y masculinas para sanar el cuerpo, la comunidad y el territorio. Incluso Yilena elabora un paralelo entre la negación del poder femenino ocurrido en la Biblia católica y la denigración de signos del poder femenino en la historia muisca, principalmente llevada a cabo en la connotación negativa de palabras de lengua muisca que fueron incorporadas al castellano del altiplano cundiboyacense.

Se habla casi siempre de María y de algunas santas, pero no se habla mucho de la importancia de las mujeres como tal, entonces a María Magdalena se le empezó a considerar como prostituta. Pero nadie habla que María Magdalena fue la preciada apóstol de Jesús y que Jesús le entregó todo su conocimiento. Ella tuvo que huir porque los hombres le hicieron una persecución, nadie habla de eso la historia pero todos consideran a María Magdalena como una prostituta porque la misma sociedad patriarcal la denigró y quiso bajar su estatus de conocimiento y sabiduría. Era una mayora también. Entonces pasó lo mismo acá con muchas cosas con las 'guarichas', ${ }^{4}$ cuando comenzó también a utilizarse el término, la lengua, para denigrar también a las mujeres. La 'cuca', la cuca se usa hoy como 'la cuca, yo no sé qué', pero las cucas para el muisca

4 En el castellano cotidiano del centro de Colombia, "guaricha" es un término empleado para referirse a una mujer "fácil" y de valores morales dudosos. En los procesos actuales de rescate de la lengua muisca, se reivindica como un término positivo que denota a una mujer "compañera" y "poderosa espiritualmente". 
eran no solo la parte sexual femenina sino las cuevas, ¿y que eran las cuevas? Eran los centros de formación espiritual de las mayoras, de las 'sagas', ¿dónde se metían las 'fuchas', ${ }^{5}$ las mayoras muiscas? En las cucas, en las cuevas, eso se puede comprobar por ejemplo en el cerro de Guadalupe. En el cerro de Guadalupe hay muchas cuevas en las que las mujeres, a las sagas muiscas las formaban desde ahí (Yilena, comunicación personal, septiembre 5 de 2015).

María Magdalena, desde la perspectiva de Yilena, era una guaricha: tomada como prostituta cuando en realidad era una compañera sabedora y mujer de poder. Es precisamente ese rol de compañera y sabedora de poder la que las mujeres muiscas reclaman para sí. Por esa razón, de la misma manera en que comunidades indígenas externas han contribuido a transmitir prácticas y valores referenciales para la indigenidad muisca contemporánea, las mismas han servido a nuestras interlocutoras como reflejo de las prácticas que buscan transformar.

Porque en todos los pueblos en donde he ido la mujer allá no tienen ni voz ni voto. Allá la mujer es como la compañía. Pero yo por ejemplo en otros pueblos he visto que la mujer, cuando se sientan los hombres en el cusmuy ${ }^{6}$, y no hay maloca pa' mujer, a las mujeres la sientan por allá, por allá arrinconadas. Y ellas duran allá toda la noche. Pueden tejer o si no se acuestan a dormir, pero ellas allá no hablan, no participan. Y ellas toda una noche sentadas, y mientras tanto los hombres están mambeando ${ }^{7}$, están hablando, están organizando y todo eso. Inclusive, en varias ocasiones que yo trasnoché, lo mismo, a nosotras no nos preguntaban nada, no nos daban participación. Entonces yo en muchas ocasiones decía: 'bueno, si a

5 Los términos “sagas" y "fuchas" también denotan positivamente a mujeres de poder espiritual en la lengua muisca interpretada en la actualidad.

6 Cusmuy, como ya lo referimos anteriormente, es el nombre dado a una casa o bohío sagrado en honor al agua.

7 "Mambear" es un verbo empleado para referirse al acto de mascar coca ritual y socialmente. 
nosotras las mujeres no nos dan participación, pues para qué nos tienen aquí toda la noche, ¿pa' estarnos sentadas?'. Eso no debe ser así. Y más que todo decía yo: ‘la compañera, ¿no?’ Uno decía: ‘la compañera, al menos siéntela al pie'. Entonces no era la compañera porque la dejaban allá como otra mujer más. Entonces eso es lo que hemos estado haciendo ahora el cambio (Cecilia Chiguasuque, comunicación personal, septiembre 5 de 2015).

Cuando las afirmaciones de Cecilia se ponen en diálogo con las de Yilena, encontramos una tendencia discursiva de la reivindicación femenina indígena: es necesario un cambio, incluso si eso significa revisar y transformar conceptos, mitos y prácticas muy arraigadas en las comunidades y que siempre se han presentado como intocables. De manera coherente con el rol que hemos identificado en lo femenino respecto al primer momento de las narrativas mitológicas-históricas muiscas, el cosmos y la sociedad se crearon gracias al poder de las entidades femeninas, de la Madre, en conjunción complementaria con su compañero astral pero aportando ese poder originario. De ahí que Yilena explique la negación y denigración femenina dada a medida que la historia avanza como una reacción masculina de temor frente a la fuerza de la mujer:

Entonces todo empezó a rebajar desde ese sentido y tiene que ver también con un miedo. Yo siempre lo he denominado así. Hay un miedo profundo dentro del pensamiento patriarcal hacia el poder de la mujer. Por eso también se empezaron a eliminar, empezaron a crearse pensamientos erróneos por ejemplo hacia la menstruación de la mujer. Hoy vemos que muchos pueblos indígenas, por ejemplo la mujer no puede estar menstruando en muchas de sus prácticas, cuando eso no era así. Al contrario, la mujer menstruaba y era más fuerza en el trabajo. Lo vemos en las comunidades yageceras [...] el desprecio hacia la sangre menstrual, hacia el valor de una mujer en embarazo, todo el poder que tiene (Yilena, comunicación personal, septiembre 5 de 2015). 
Acorde con la dualidad y la complementariedad exigida por las mujeres muiscas como base fundamental del rescate de su identidad cultural étnica, esta expresión de feminismo indígena demanda que la reivindicación de la fuerza y poder femenino no se logre mediante la inversión del orden jerárquico de los géneros, sino mediante su confrontación y subversión.

[...] también debe haber un control de parte de la mujer para que no se vaya al extremo. Y el irse al extremo me refiero a no llegar con un discurso a juzgar siempre al hombre porque no es que: 'los hombres, los hombres, los hombres...', 'Los hombres hacemos esto las mujeres aquello', me parece que ya es un extremo. Las mujeres ya se han ido a un discurso al extremo. Y siento que nosotros como mujeres muiscas, hombres muiscas, hemos venido encontrando que definitivamente hay que hacer un equilibrio (Yilena, comunicación personal, septiembre 5 de 2015).

El "equilibrio", término frecuentemente usado en contextos de análisis y demandas políticas de igualdad y equidad social -incluidas las de género- en el presente caso estudiado se relaciona con la necesidad de que ese poder femenino, identificado y legitimado en las figuras de las entidades "Madre" y ancestros astrológicos, debe aportar su poder al flujo energético compuesto también por el poder y fuerza de lo masculino.

$\mathrm{Al}$ igual que la copulación primordial que dio origen al universo muisca, mujeres y hombres de poder deben aportar sus potencias sanadoras contenidas en su sexualidad. No en vano hemos sospechado e identificado la relación existente entre medicina muisca y sexualidad incluso en el humor que emerge en la cotidianidad de las ceremonias de saludo, agradecimiento y pagamento. Aportando sus "ovarios" y “matrices", las mujeres demandan una posición equitativa en los espacios de curación comunitaria.

Nosotras hemos aprendido que tenemos como la más fuerza, como que somos las que... Todo lo que nos han enseñado, lo del poder 
de la mujer, la fuerza que tiene la mujer, el consejo o la palabra que tiene la mujer, entonces yo decía: 'entonces si tenemos todo eso, entonces ¿nosotras por qué no podemos estar ahí con ustedes?’ [...] Alcánceles uno el alimento, la chicha. Entonces que no nos inviten, que sigan los hombres solos porque pa' qué nos invitan. Trasnochar y todo para que, ellos hablan todo lo de su caminar pero no nos dejan participar. Y si dicen que tenemos más, que por ser mujeres les ayudamos y les damos más la fuerza, entonces ¿por qué nosotras no podemos estar con ustedes? (Cecilia Chiguasuque, comunicación personal, septiembre 5 de 2015).

Nuevamente, aunque las matrices materializadas en la totuma de chicha y la olla de alimentos hacen parte de los aportes del poder femenino, las mujeres muiscas comienzan a considerar que su participación activa en el manejo de plantas medicinales debe fortalecerse. De manera breve, debemos explicar que las complementariedades entre lo femenino y lo masculino se presentan y fluctúan constantemente en el uso de medicinas y bebidas sagradas muiscas. En una etnografía publicada anteriormente (Gómez, 2011), explicamos cómo el tabaco y la chicha, por ejemplo, se manifiestan como cartografías de lo femenino y lo masculino. El tabaco, planta primordialmente masculina, activa tanto el pensamiento (masculino) como el amor (femenino); incluso su tamaño puede mostrar que un tabaco puede ser hembra (grande) o macho (pequeño) como ocurre en las proporciones y tamaños en varias especies animales. Respecto a la chicha, bebida de fuerza femenina, en algunos grupos muiscas de hoy, mientras el vocablo chi es masculino cha es femenino (pp. 72-73). ${ }^{8}$

Estas cartografías, en últimas, sugieren la presencia constante de la complementariedad entre lo femenino y lo masculino en los flujos energéticos que mantienen la reproducción social de las comunidades.

8 Debemos tener en cuenta que la cartografía compuesta por chi y cha es una interpretación reciente y actual, además de no ser aceptada por todas las comunidades y grupos muiscas, pues la palabra “chicha” proviene de la lengua quechua. El término muisca para la bebida fermentada de maíz es fapqua. 
Vimos en un apartado anterior la complementariedad entre los roles medicinales de John Orobajo como hombre líder de Bosa y los de Cecilia y Myriam en una ceremonia realizada en el humedal Chiguasuque. Mientras el primero poporeaba, las otras manejaban el tabaco. La cartografía se propaga sistemáticamente, pues en el caso del poporo, que es un calabazo que guarda cal en su interior y que es frotado constantemente con un palo o chuguna, el hombre de medicina "penetra" el calabazo y toma cal para ser depositada en la boca para que se mezcle con las hojas de coca que se mascan o mambean. De esta manera el poporo es falo y útero a la vez, la cal la semilla masculina sacada de la concha del caracol (símbolo femenino) y la coca una planta de mujer que debe ser activada por la saliva del hombre y su semilla.

Poporear, a los ojos de quien analiza ese trabajo desde afuera, es un ejercicio permanente de copulación activadora de fuerzas femeninas y masculinas guardadas en los elementos de la medicina. Consecuentemente, y como lo explicamos en una etnografía anterior sobre repertorios de pagamentos en territorios muiscas (Gómez, 2016), mientras los hombres de medicina y poporo conducen el trabajo de curación personal, comunitario y territorial, las mujeres entregan algodones a los participantes para recoger y "tejer" los pensamientos y propósitos colocados en ese trabajo, para finalmente recogerlos. De esta manera, los roles femeninos y masculinos se van repartiendo y poniendo en fluctuación constante. En el marco de tales complementariedades, Yilena reafirma la necesidad de que se fortalezcan los roles femeninos en la medicina muisca.

Y también hemos venido comprendiendo que el hombre sin el trabajo y la energía que pone la mujer... entonces por ejemplo lo que hizo con John. John dirigió hoy la ceremonia, pero doña Cecilia fue la que manejó el tabaco y yo fui la que manejó los algodones. $\mathrm{Y}$ eso no hubiera tenido el mismo poder sino hubiera estado eso ahí. Entonces estamos nuevamente tratando de empezar eso, de recuperar ese carácter que tenía la mujer y que la mujer también se empiece a apropiar. Por ejemplo hay algo que es muy notable dentro del pueblo muisca y tiene que ver con que nunca se habla de mujeres médicas tradicionales, eso (es) algo de lo que no se habla en toda la comunidad muisca. Pero tiene también que ver con 
que las mujeres no han empezado a ejercer un empoderamiento para prepararse como tal. Tiene que ver también con que los espacios han sido cerrados y han sido netamente masculinos, entonces casi siempre que llega, no sé, por ejemplo, un mamo, siempre cogen a los hombres para los procesos de formación, muy pocas veces vienen las sagas a hacer procesos de formación (Yilena, comunicación personal, septiembre 5 de 2015).

La palabra "mamos" hace presencia constante en el discurso muisca de hoy debido, a como lo hemos explicado anteriormente, a la colaboración que estas autoridades espirituales de las culturas de la Sierra Nevada de Santa Marta han tenido en los procesos etnopolíticos y de rescate espiritual muisca. Fueron ellos quienes iniciaron en el manejo del poporo a varios hombres líderes de medicina en Bogotá y el altiplano cundiboyacense. Debido a eso sus enseñanzas son citadas constantemente e incorporadas tan fuertemente por hombres muiscas hasta convertir a los mamos en figuras de referencia mimética: los hombres de medicina muisca se parecen mucho en su indumentaria y repertorios a ellos.

Pero la referencia que hace Yilena en su relato anterior a los mamos no solo permite reclamar por la discriminación hacia la mujer en los procesos de enseñanza intercultural de la medicina indígena. Cuando traemos a colación algunos conceptos transmitidos por los mismos mamos a los muiscas, también nos invita a prolongar las cartografías de lo femenino y masculino para comprender más las contradicciones que legitiman las demandas de las mujeres muiscas. En una ocasión se llevó a cabo una reunión de varios líderes de comunidades muiscas con mamos kaggaba (koguis), ika (arhuacos) y wiwas en el Templo del Sol, construcción monumental en el Museo Arqueológico de Sogamoso. En el marco de la Fiesta del Zocán, un mamo kaggaba enseñaba que el rol de un hombre de medicina (mamo) era "recoger" el poder gestor de la mujer para contribuir a armonizar y equilibrar los flujos vitales.

Es decir, que siendo hombres, el poder de los mamos yacía en la fuerza que permite a lo femenino dar a luz. A esa capacidad tan compleja los kaggaba la denominan dumburru. Dum es la fuerza y la fortaleza que llevan a la comprensión, el entendimiento y la sabiduría. Para lograrla, los mamos deben estar casados, pues deben poder contar con la fuerza 
de la mujer. $B u$ significa la fuerza del nacer, del crecer, del germinar y de reproducir. Rru es espíritu y pensamiento. En suma, proponemos una interpretación arriesgada en la que por medio de esa fuerza y poder denominado dumburru en la Sierra Nevada, el hombre-medicina cultiva es espíritu y pensamiento que permite comprender, ganar sabiduría e interactuar con los flujos reproductivos y vitales de la Madre Tierra, por medio de la fuerza complementada por la mujer en el matrimonio.

Sin embargo, tales enseñanzas realzan los reclamos de Cecilia, pues, como citamos anteriormente, lo que ella vio en otras comunidades indígenas, incluidas las de la Sierra, fueron mujeres pasivas y poco integradas a los espacios sociales y medicinales. Fue la misma Cecilia quien nos compartió la manera en que los espacios de formación en medicina indígena y manejo de plantas medicinales llegaron a su comunidad en Bosa. Su relato es representativo de los contenidos históricos encontrados en varias comunidades muiscas actuales que han permitido identificar un campo muy relevante hoy en su(s) reetnicidad(es), el cual llaman “espiritual”. Brevemente diremos que lo espiritual corresponde a una dimensión de la indigenidad que muestra su lado místico, religioso y moral; que se explaya en expresiones estéticas muy perceptibles en todos los sentidos, principalmente el visual y el sonoro; que genera ciertas militancias basadas no tanto en la organización político-administrativa de las comunidades, sino en la conformación de grupos y redes que comparten conceptos, prácticas y repertorios medicinales y místicos.

Como era de esperarse en medio de comunidades católicas acérrimas, la incorporación de tales prácticas y la conformación de un campo espiritual en Bosa no fue nada fácil. Cecilia, incluso, elabora un diagnóstico a su manera:

[...] que sumercé vea que la gente se sienta en un cusmuy o que tengan que trasnochar, no. Ellos no creen todavía en el proceso de nosotros, ellos dicen: ‘¿qué es eso de lo espiritual?’, ‘¿Ustedes lo que se volvieron fue brujas?'. Ellos lo toman por malo, y ahorita que nos ven haciendo ambil... Y por ejemplo un día que estábamos con la comunidad y yo me saqué esto (saca su tarrito con ambil) me dijeron: 'oiga Cecilia, ¿qué está chupando ahí?', 'Estoy chupando una planta sagrada que se llama tabaco', 'o sea que ya 
se cansaron de estar chupando marihuana'. Y yo a veces me pongo a hablar con ellos y: 'usted sí que se pone hablar pendejadas', y yo: 'ahhhh'. Y no les gusta, por ejemplo a las mayores usted no le asienta en un cusmuy, ellas no saben qué es eso. Y entonces cuando yo me vine que me decían abuela y que la abuela y que la abuela entonces como yo me salí del cabildo pusieron a una más mayor que yo pero ella usted la ve y no maneja nada de eso. Ellos le preguntan algo de lo espiritual y no lo sabe (Cecilia Chiguasuque, comunicación personal, septiembre 5 de 2015).

Hasta de "brujas" son calificadas algunas mujeres indígenas que deciden rescatar prácticas medicinales. El término medieval indica la doble condición de marginalidad que históricamente se inserta en ellas: son paganas y mujeres. Por esa razón, a ese dolor natural del parto, la menstruación y todos los trabajos femeninos que involucran la generación de vida, Yilena nuevamente suma, al igual que Kulchavita y otros hombres líderes, el dolor histórico de larga duración que se ha insertado en las comunidades.

Entonces nosotras tenemos que empezar a hacer ese empoderamiento, a volver a retomar esa fuerza de la mujer siempre equilibrando su palabra y reconociendo siempre en el otro, o sea en el hombre que también fue una fuerza que no todo fue malo, es que también nos quedamos como en el dolor. Es un dolor antiguo y las mujeres tenemos ese dolor. Sí, es la memoria que nos heredaron nuestras ancestras, tenemos el dolor de las violaciones, tenemos el dolor de los maltratos inclusive muy reciente, muchas de nuestras abuelas han sufrido el maltrato físico. Nosotras hemos tenido la oportunidad de ya no vivir eso, pero esa memoria aunque sea de ellas, se va creando. Entonces nosotras tenemos que también dejar un poco eso, parece que ya es exagerado, debe haber un equilibrio (Yilena, comunicación personal, septiembre 5 de 2015).

El "equilibrio", concepto obligado en la cadena semántica derivada de la dualidad y la complementariedad, no solo se refiere a las 
posiciones en equidad de los géneros. También implica la capacidad humana de comprender la armonía de los elementos de la naturaleza y el cosmos para integrarse a los flujos energéticos y contribuir a mantenerla. Por eso la armonización entre el "limpiar", “el solicitar" y el "agradecer” a los espíritus de los lugares es la clave de la medicina individualcomunitaria-territorial (Gómez, 2016). Pero tales ejercicios no son posibles sin la complementariedad de la medicina femenina y masculina.

\section{La aplicación de la medicina de mujer: la preparación del ambil}

En la medida que el campo espiritual y medicinal se fue consolidando como dimensión relevante de la reetnicidad muisca en la última década del siglo pasado, fueron los hombres quienes tuvieron el mayor privilegio de recibir las enseñanzas de mamos, taitas y otras figuras de autoridad médica-religiosa de comunidades indígenas colaboradoras. Cuando se conversa con varios miembros de comunidades sobre la memoria de los procesos de revitalización étnica reciente, emergen nombres de patriarcas y hombres iniciados en la medicina indígena que lograron con el tiempo liderazgo y reconocimiento. Surgen nombres como Carlos Manché, José Pereira, Fernando Castillo, Camilo Chautá, Kulchavita, Suayé, iniciados por taitas y mamos como Lucas, Ramón Gil, Antonio Pinto, Lorenzo Izquierdo, Orlando Gaitán, Víctor Martínez Taicoma, entre otros.

Muy pocas mujeres son nombradas cuando se recuerda la consolidación de la medicina muisca; la más nombrada es la abuela Blanca Nieves de Suba. En comunidades como Suba y Bosa se nombra orgullosamente como característica de estas la presencia de muchas mujeres en los cargos más importantes de sus cabildos; sin embargo, una frase muy repetitiva en distintos momentos de diálogo es que las mujeres han sido algo discriminadas y silenciadas en las comunidades muiscas.

Yilena, quien siempre se caracteriza por proponer que la mujer se "empodere" mediante su aporte en restaurar un equilibrio y complementariedad, dejando atrás el dolor resentido y la búsqueda de un feminismo extremo que excluya al hombre, recuerda pasajes en los que 
la participación activa de las mujeres en procesos espirituales se consolidó de manera natural.

Cuando los hombres hacen trabajo solos es más demorado. Pero cuando está la mujer fluye mucho, fluye demasiado por esa capacidad natural de la mujer de manejar su energía, la capacidad de materializar rápido las cosas [...] Algunos trabajos espirituales que estamos haciendo dentro de la corporación de abrir camino, de limpiar algunas cosas del proceso y eso, y hace poco, eso fue hace como una semana, se hizo un trabajo con unas tareas dejadas por los mamos, unas recomendaciones que salieron en consulta por parte del médico tradicional de Sesquilé que es Camilo Chautá. Antes este trabajo ya lo venían haciendo ellos solos y no se veía mucho avance, trasnochaban y trasnochaban y trasnochaban. Cuando las mujeres estuvieron el trabajo fluyó muchísimo y ellos mismos lo manifestaron. Pero de hecho esos trabajos empezaron por iniciativa de nosotras. Nosotras fuimos las que convocamos y dijimos: 'tenemos que hacer trabajo espiritual en la casa de Bosa', y fuimos las que empezamos a convocar. Eso se movió gracias a la voluntad de las mujeres. Yo no estuve. Y los hombres me lo manifestaron. Me dijeron: 'ese día el trabajo fluyó mucho cuando yo le entregaba este trabajo a doña Cecilia, a Jaqueline, a las que estuvieron'. Cuando está la mujer fluye más bonito, sin obviar esa fuerza de ellos. Igual, si estamos nosotras y no están ellos, igual (Yilena, comunicación personal, septiembre 5 de 2015).

El poder de la medicina muisca se activa mediante la complementariedad de la fuerza masculina y femenina, por eso hemos afirmado anteriormente que en el marco de prácticas rituales de curación y limpieza se llevan a cabo repertorios que por lo general reproducen la copulación primordial de los padres creadores. Un sábado del mes de septiembre del año 2015 nos desplazamos con los integrantes de la casa de medicina Zhue Gata de Bosa hacia Nemocón. En la zona veredal ubicada sobre las faldas de las colinas cercanas al casco urbano, la familia de Henry Neuta, ex gobernador indígena y hombre en proceso 
de aprendizaje de medicina, tiene un predio que ha sido empleado varias veces para reunir al grupo y realizar ceremonias de pagamento. El objetivo de la jornada, que se extendería hasta el medio día siguiente, era la preparación de una medicina con base en tabaco llamada ambil.

El proceso de preparación de esta medicina fue transmitido años atrás por Víctor Martínez Taicoma, cacique de la comunidad huitoto de la Chorrera en el Amazonas. Quienes han sido iniciados (as) la portan en tarros pequeños o totumos que depositan en sus mochilas y sirve para curaciones individuales, comunitarias y territoriales, pues aunque se carga individualmente puede compartirse, se prepara colectivamente y en su proceso se integran las fuerzas sanadoras de los territorios de donde provienen las plantas medicinales y del lugar donde se prepara. Suele prepararse cuando el colectivo va a iniciar un proyecto o a definir una "unidad-propósito-compartida" (Gómez, 2015); sirve para dialogar sobre problemáticas, conflictos y su resolución; contribuye a que cada persona revise en su historia personal temas por concluir y virtudes por descubrir.

La entrega del ambil y la autorización para su preparación comunitaria va acompañada de la transmisión del mito de origen de la medicina. Debido al acuerdo de confidencia pactado con los miembros de Zhue Gata, no podemos escribir ni analizar el mito con profundidad, pero sí parafrasearemos a nivel general la historia contada y sus enseñanzas. Todo arranca con la pareja, pues en la historia un hombre casado vivía cometiendo actos que irrespetaban a su compañera. La mujer decide irse y cuando el hombre comienza a extrañarla le pide que vuelva al hogar. Es la parte de la historia que deja claro el rol "ordenador" de la mujer, pues ella le solicita paulatina y progresivamente varias tareas que encadenadas corresponden al proceso que lleva a cabo una persona en la preparación del ambil: revisión de su mundo interno, siembra, cuidado y cosecha de la planta de tabaco, recolección de hojas y la preparación de la medicina.

En últimas, el ambil es la "sangre del tabaco". Su apariencia es cremosa y gelatinosa y se consume al chuparla lentamente. El ingrediente principal son hojas de tabaco. Suelen ser recogidas y acumuladas de plantas de varias huertas comunitarias o, cuando hay escasez, suelen ser donadas por otras comunidades. Las hojas se lavan y se alistan 
para ser hervidas. Dependiendo del territorio y de la comunidad que prepara el ambil, otros ingredientes hacen parte de la medicina. En la Sierra Nevada, por ejemplo, debe ser mezclado con sal. Los muiscas de Bogotá y la sabana integran una planta nativa que, al dialogar con el grupo, resultó ser el elemento activador de medicina: el hayuelo.

De la misma manera que la fuerza del hombre mamo reside en su mujer, la fuerza del tabaco en el ambil es activada por el hayuelo. Aunque en un principio se pensaba que el hayuelo se empleaba simplemente para endulzar el sabor amargo y fuerte de la gelatina de tabaco, Yilena contaba que Ramón Gil, quizá el líder más importante de los mamos serranos, explicaba que "el hayuelo contenía el espíritu masculino". Consecuente con el cuidado de la dualidad y complementariedad de los géneros, el hayuelo, espíritu masculino, es recolectado por mujeres y son ellas quienes dirigen su deshojado. La repartición de géneros en la relación esencia-uso también se da, explicaba Yilena, en el mambe de coca, que siendo "palabra de mujer", es consumida y trabajada principalmente por los hombres al poporear.

Figura 9. Recolección de hayuelo

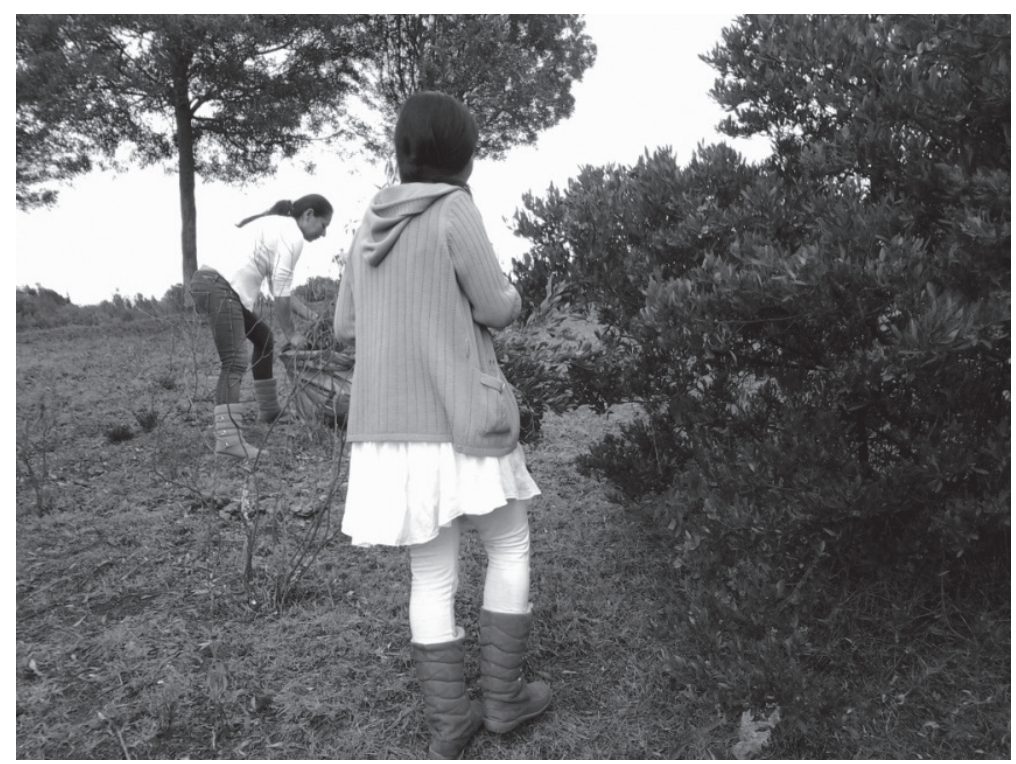

Fotografía de Pablo F. Gómez Montañez. Mujeres muiscas —en primer plano Yilenarecolectan ramas de hayuelo para la preparación ambil. 
Figura 10. Limpieza de tabaco

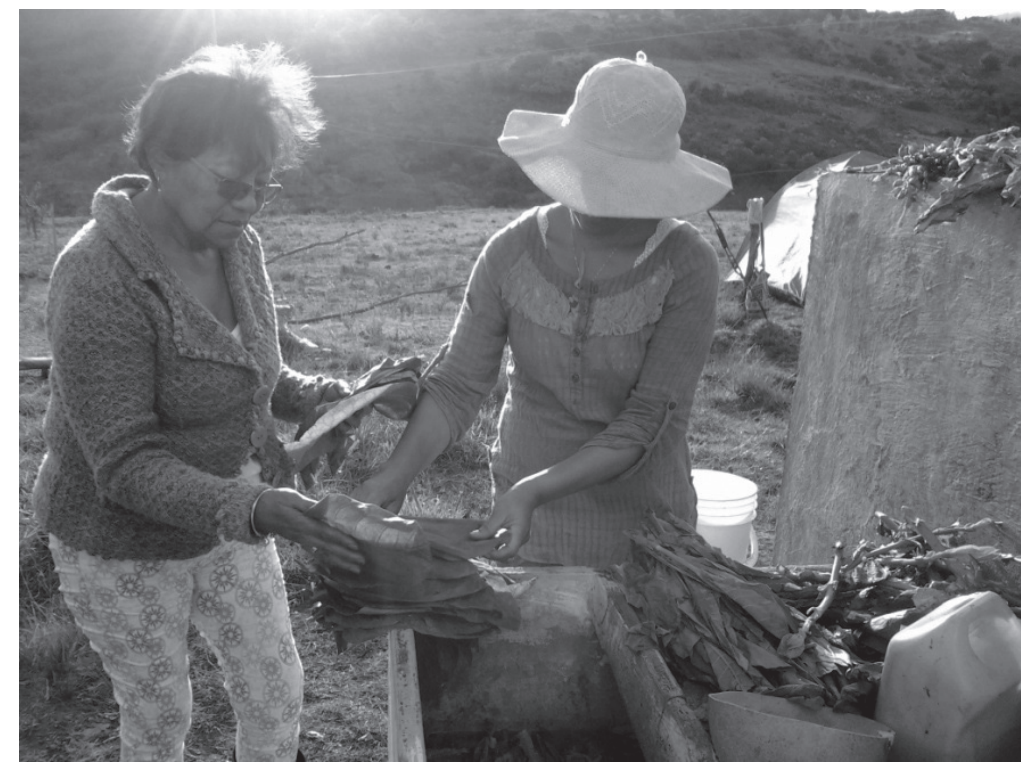

Fotografía de Pablo F. Gómez Montañez. Limpieza de hojas frescas de tabaco para preparación de ambil. Dioselina lidera la labor.

Figura 11. Preparación del hayuelo

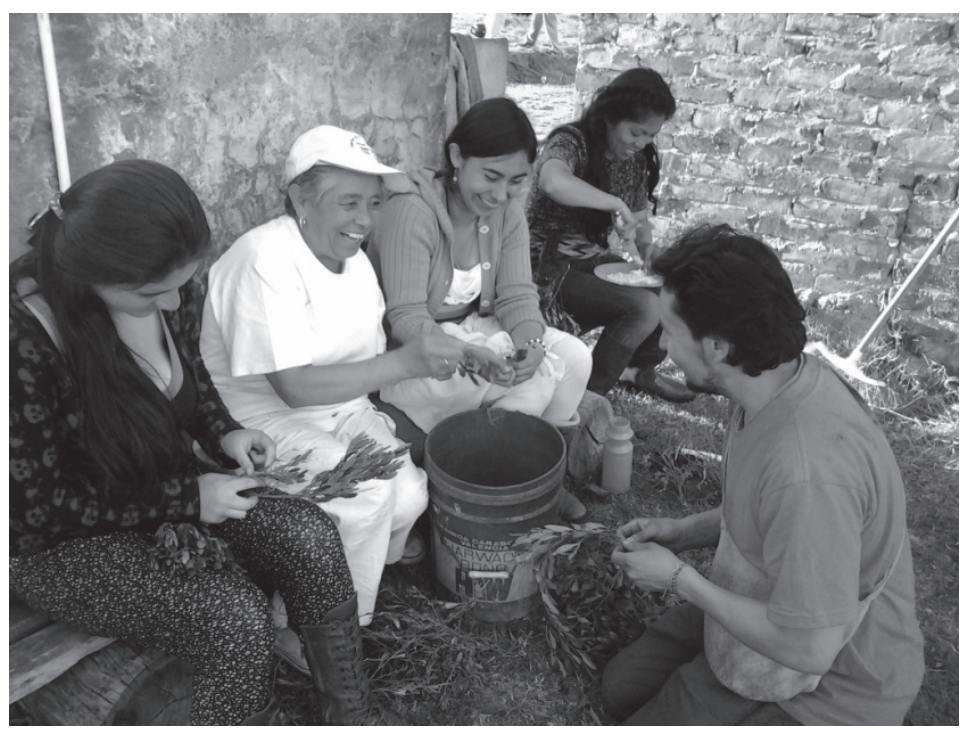

Fotografía de Pablo F. Gómez Montañez. Integrantes de Zhue Gata y del Semillero de Investigación $A b a$ Ye deshojan ramas de hayuelo para preparación del ambil. 
Cuando se pone el sol en el ocaso, comienza la ceremonia de preparación del ambil. Se enciende el fuego. Las hojas de tabaco y hayuelo, en conjunción, en complementariedad, se ponen a hervir en una olla grande. Mientras tanto, los hombres de medicina como John Orobajo lideran la reflexión y comunicación colectiva en torno a los propósitos que se colocan en la preparación de la medicina. El ambil, entonces, va a contribuir al logro de tales propósitos que por lo general corresponden al crecimiento personal y al aprendizaje comunitario. Al igual que lo describimos en el capítulo anterior, se realiza una limpieza a cada persona mediante el soplo de josca, la cual es "rezada" mediante humo de tabaco por parte de Cecilia y dada por John. Hay cánticos y danzas alrededor del fuego. Hay momentos de humos, de reflexión y de mucho silencio. Pese al cansancio, la idea es que ningún participante se duerma, sino que vele toda la noche para que el ambil "recoja" la fuerza y el propósito de todo el grupo.

Como suele suceder en otras ceremonias de medicina indígena como el yagé, se busca que la primera limpieza que ocurra sea la del cuerpo físico. Los estornudos y sonadas fruto de la soplada de josca hacen parte de ello. Pero en el marco de la preparación de ambil, las mujeres toman un poco del agua hervida de la olla y explican que, al igual que la leche materna, el tabaco ofrece un líquido poderoso al que denominan chicha de tabaco. Invitan a los participantes a acercarse y a tomarla. Por medio del humor recuerdan ocasiones en la que hubo, en palabras de uno de ellos, una "cagada colectiva". Por supuesto, eso se debe a que la chicha de tabaco es un purgante efectivo. Una vez las personas se han limpiado físicamente y han comenzado a armonizarse mediante los cánticos y danzas, llega otra fase importante del proceso.

Aproximadamente a media noche, cuando las hojas de tabaco y hayuelo se han cocinado muy bien y han soltado sus esencias líquidas, se procede con un trabajo importante tanto para lograr el producto como para curar individual y colectivamente. La gran olla se saca de la fogata y se coloca cercana a un poste. En este se ha colgado un costal que sirve de tamiz. Con una cuchara de madera se toman masas de hojas, se ponen en el tamiz y se retuercen hasta exprimir al máximo el agua oscura que cae en otra olla. Los líderes invitan a que cada participante ayude a exprimir masas de hojas, pues la idea es que la salida 
de fluidos "limpia" a cada persona de sus energías negativas guardadas en recuerdos tristes, deudas morales pendientes y deseos no gratos.

Por tanto, es un ejercicio de sanación: el ambil debe recoger los propósitos de curación de cada persona y, a manera de un tejido, conforma una medicina colectiva. Debido a eso durante la exprimida pueden emerger varios estados de ánimo en quienes hacen la labor, pero siempre son apoyados alegremente por los demás. La preparación del ambil puede pasar de momentos muy místicos a otros más informales pero que no desarmonizan con la atmósfera ritual.

Una vez se recoge el agua tamizada, la esencia del tabaco y el hayuelo pasa por tres ollas, una grande, una mediana y una pequeña, a medida que el hervor constante va concentrando la sustancia hasta tornarla viscosa. El resultado es el ambil o gelatina de tabaco, la cual será acumulada por los hombres líderes de medicina y repartida posteriormente a quienes estén autorizados para usarla. Quiere decir que incluso aquellos que no la pueden consumir también han aportado su fuerza sanadora y que, pese a no poder chuparla, la medicina los ha curado durante su preparación, gracias a su aporte activo.

Figura 12. Altar durante preparación del ambil

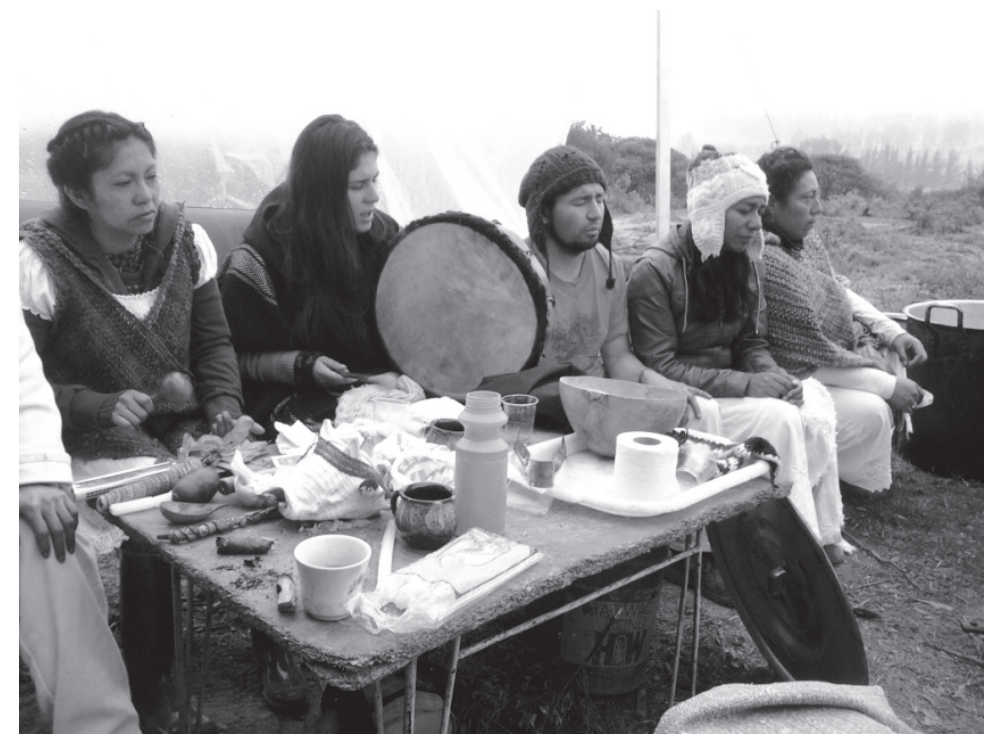

Fotografía de Pablo F. Gómez Montañez. Altar con medicinas repartidas durante la preparación del ambil. Participantes cantan y tocan instrumentos. 
Figura 13. Fase final del ambil

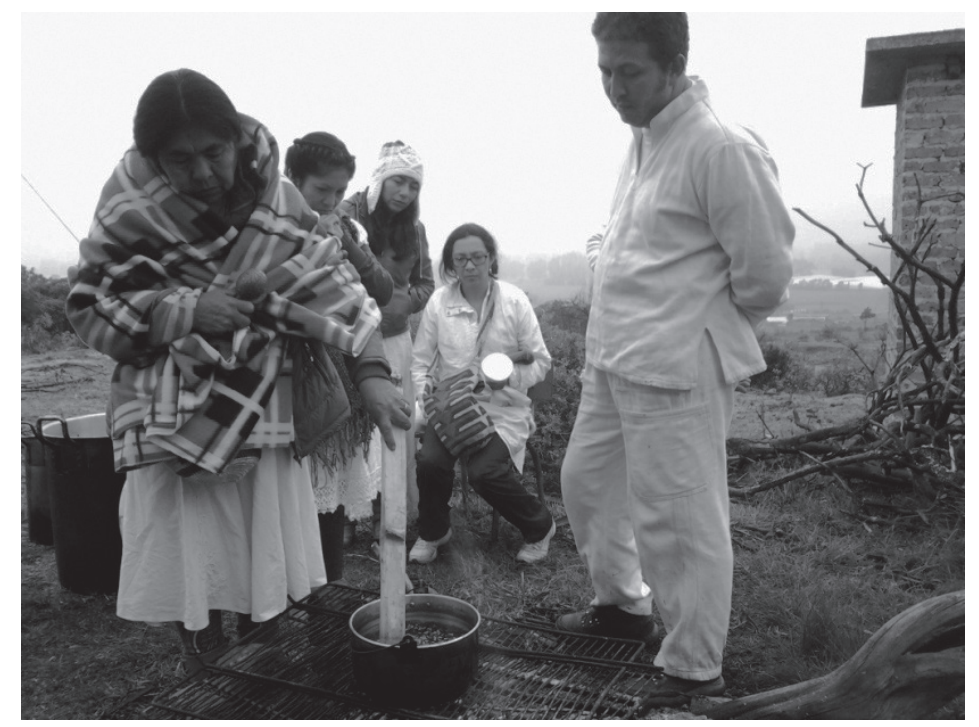

Fotografía de Pablo F. Gómez Montañez. La abuela Cecilia revisa y revuelve el ambil en su fase final de preparación.

Figura 14. Ambil en fase final

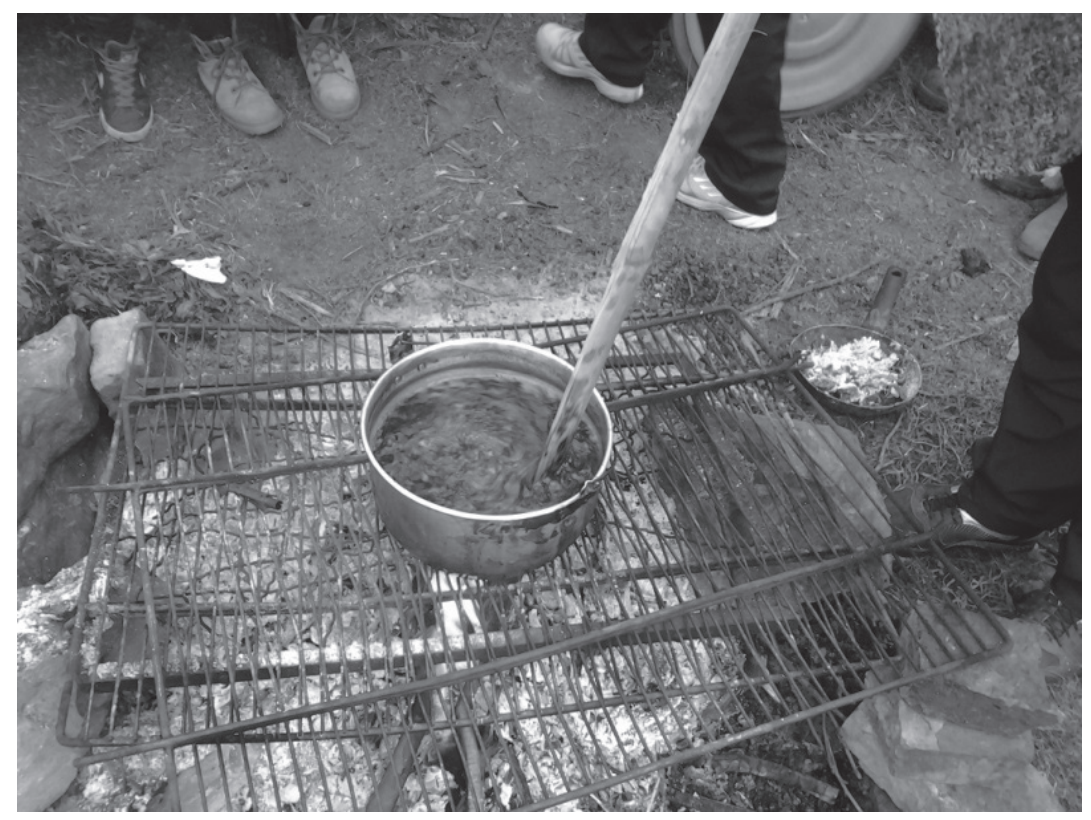

Fotografía de Pablo F. Gómez Montañez. El ambil en su fase final de hervor. 
En suma, el rol de la mujer en los procesos de memoria muisca se basa en un proceso complejo de interpretación histórica que finaliza sustentando el poder femenino en la medicina. Entender el proceso implica comprender, en primera medida, que la contención de la memoria de largo aliento ha sido llevada a cabo por la mujer a través de su matriz y que tal responsabilidad significó maltrato, dolor y sufrimiento. Tales vejaciones hacia la mujer exigen la limpieza "espiritual" de la matriz y la semilla para que el "despertar muisca" sea posible.

La historia registrada por los cronistas de la Conquista colocó a las entidades femeninas como originarias y primordiales, para luego obligarlas a asumir una posición sumisa ante el poder solar masculino que además las condenó a ser relacionadas como figuras del desorden social y moral. Los muiscas de hoy no ven al poder lunar como opositor, sino como confrontador, ordenador y colaborador del poder del hombre. El feminismo indígena, de acuerdo con Yilena, no debe procurar la imposición de la mujer sobre el hombre, sino la consolidación de un lugar que le permita a la mujer un rol más activo en los diferentes procesos políticos, sociales y culturales desde donde se rescata la memoria e identidad étnica contemporánea.

Finalmente, podemos afirmar que la relación entre la mujer y la memoria muisca no radica exclusivamente en las acciones reivindicativas llevadas a cabo por las primeras en aras de confrontar la historia, el patriarcado ancestral y mantener la reproducción social de sus comunidades, sino en la aceptación de la existencia de un "poder femenino" que se relaciona con varios elementos del universo místico y cotidiano muisca. Tal poder femenino yace, incluso, en el mundo interno de los hombres, por lo cual la relación memoria-mujer trasciende al ser humano para alojarse en cadenas significativas que configuran principios y reglas morales de convivencia y armonización entre los humanos y la naturaleza.

En ese orden de ideas, la matriz que permitió que el muisca de hoy despertara en el rostro del enemigo, se replica en cada sujeto que ha optado por reconocerse indígena y elaborar día a día su indigenidad. La memoria, entonces, no es que sea un asunto de mujeres, sino que se mantiene, transmite y reproduce en la medida que cada cual sea consciente de la dualidad entre lo femenino y lo masculino que 
se presenta y replica sistemáticamente en cada ser, en cada cosa y en cada principio. La memoria se torna curación y medicina en la medida que cada quien logra complementar y canalizar ambos poderes. Solo así, se logrará limpiar la matriz y continuar aquello que los ancestros guardaron en esta para resistir y despertar. 
